\title{
Tissue-resident memory CD8 T-cell responses elicited by a single injection of a multi-target COVID-19 vaccine
}

\author{
V. Gauttier ${ }^{1, \dagger}$, A. Morello ${ }^{1, \dagger}$, I. Girault ${ }^{1, \dagger}$, C. Mary ${ }^{1, \dagger}$, L. Belarif ${ }^{1}$, A. Desselle ${ }^{1}$, E. Wilhelm ${ }^{1}$, T. \\ Bourquard $^{2}$, S. Pengam ${ }^{1}$, G. Teppaz ${ }^{1}$, V. Thepenier ${ }^{1}$, K. Biteau ${ }^{1}$, E. De Barbeyrac ${ }^{1}$, D. \\ Kiepferlé $^{1}$, B. Vasseur ${ }^{1}$, FX. Le Flem ${ }^{3}$, D. Debieuvre ${ }^{4}$, D. Costantini ${ }^{1}$, N. Poirier ${ }^{1, *}$.
}

${ }^{1}$ OSE Immunotherapeutics, Nantes, France

${ }^{2}$ MabSilico, Tours, France.

${ }^{3}$ Bataillon de Marins Pompiers de Marseille (BMPM), Marseille, France.

${ }^{4}$ Service de pneumologie, groupe hospitalier régional Mulhouse-Sud Alsace (GHRMSA), Mulhouse, France.

${ }^{\dagger}$ These authors contributed equally to the first authorship of this study.

*Correspondence should be addressed to:

Dr. Nicolas Poirier

OSE Immunotherapeutics

22 Boulevard Benoni Goullin

44200 Nantes, France

Tel: +33(0) 228291010

Email:nicolas.poirier@ose-immuno.com

Key words: vaccine, SARS-CoV-2, COVID-19, memory T lymphocytes, Trm

The authors of this manuscript have conflicts of interest to disclose: V.G., A.M., I.G., C.M., D.C. and N.P. are authors of a patent related to SARS-CoV-2 vaccine and shareholders of OSE Immunotherapeutics, a company owning SARS-CoV-2 vaccine technology. 


\section{Abstract}

The COVID-19 pandemic is caused by severe acute respiratory syndrome coronavirus-2 (SARS-CoV-2) which enters the body principally through the nasal and larynx mucosa and progress to the lungs through the respiratory tract. SARS-CoV-2 replicates efficiently in respiratory epithelial cells motivating the development of alternative and rapidly scalable vaccine inducing mucosal protective and long-lasting immunity. We have previously developed an immunologically optimized multi-neoepitopes-based peptide vaccine platform which has already demonstrated tolerance and efficacy in hundreds of lung cancer patients. Here, we present a multi-target CD8 T cell peptide COVID-19 vaccine design targeting several structural $(\mathrm{S}, \mathrm{M}, \mathrm{N})$ and non-structural (NSPs) SARS-CoV-2 proteins with selected epitopes in conserved regions of the SARS-CoV-2 genome. We observed that a single subcutaneous injection of a serie of epitopes induces a robust immunogenicity in-vivo as measured by IFN $\gamma$ ELIspot. Upon tetramer characterization we found that this serie of epitopes induces a strong proportion of virus-specific CD8 T cells expressing CD103, CD44, CXCR3 and CD49a, the specific phenotype of tissue-resident memory T lymphocytes (Trm). Finally, we observed broad cellular responses, as characterized by IFN $\gamma$ production, upon restimulation with structural and nonstructural protein-derived epitopes using blood $\mathrm{T}$ cells isolated from convalescent asymptomatic, moderate and severe COVID-19 patients. These data provide insights for further development of a second generation of COVID-19 vaccine focused on inducing lasting Th1biased memory CD8 $\mathrm{T}$ cell sentinels protection using immunodominant epitopes naturally observed after SARS-CoV-2 infection resolution. 


\section{Statement of Significance}

Humoral and cellular adaptive immunity are different and complementary immune defenses engaged by the body to clear viral infection. While neutralizing antibodies have the capacity to block virus binding to its entry receptor expressed on human cells, memory T lymphocytes have the capacity to eliminate infected cells and are required for viral clearance. However, viruses evolve quickly, and their antigens are prone to mutations to avoid recognition by the antibodies (phenomenon named 'antigenic drift'). This limitation of the antibody-mediated immunity could be addressed by the T-cell mediated immunity, which is able to recognize conserved viral peptides from any viral proteins presented by virus-infected cells. Thus, by targeting several proteins and conserved regions on the genome of a virus, T-cell epitope-based vaccines are less subjected to mutations and may work effectively on different strains of the virus. We designed a multi-target $\mathrm{T}$ cell-based vaccine containing epitope regions optimized for CD8+ $\mathrm{T}$ cell stimulation that would drive long-lasting cellular immunity with high specificity, avoiding undesired effects such as antibody-dependent enhancement (ADE) and antibody-induced macrophages hyperinflammation that could be observed in subjects with severe COVID-19. Our in-vivo results showed that a single injection of selected CD8 T cell epitopes induces memory viral-specific $\mathrm{T}$-cell responses with a phenotype of tissue-resident memory $\mathrm{T}$ cells (Trm). Trm has attracted a growing interest for developing vaccination strategies since they act as immune sentinels in barrier tissue such as the respiratory tract and the lung. Because of their localization in tissues, they are able to immediately recognize infected cells and, because of their memory phenotypes, they rapidly respond to viral infection by orchestrating local protective immune responses to eliminate pathogens. Lastly, such multiepitope-based vaccination platform uses robust and well-validated synthetic peptide production technologies that can be rapidly manufactured in a distributed manner. 


\section{Introduction}

COVID-19, the infectious disease caused by the zoonotic coronavirus SARS-CoV-2, is a global pandemic which has infected more than 16 million of individuals and already caused up to 650 000 deaths worldwide as of end of July 2020. The severity of the COVID-19 outbreak highlights the need to develop therapeutic interventions including fast and efficacious prophylactic vaccines. Previous severe outbreaks of coronavirus (CoVs) have emerged including Severe acute respiratory syndrome CoV (SARS-CoV-1) in 2002 and Middle East Respiratory Syndrome CoV (MERS-CoV) in 2012. Learnings from current (SARS-CoV-2) and previous (SARS-CoV-1, MERS-CoV) infections argue that the body develops humoral and cellular immune responses against this type of respiratory viruses but that antibody responses are shortterm $^{1-5}$ in contrast to the cellular immunity which is still observed 11 and 17 years after the infection $^{6,7}$.

Current and previous CoVs vaccine strategies have been almost exclusively focused on eliciting a humoral immune response, particularly anti-Spike neutralizing IgG antibody. However, the generation of non-neutralizing antibody responses $^{8}$, insufficient antibody titers ${ }^{9}$, Th2-biased immune response or glycosylation changes in the $\operatorname{IgG~Fc~tail~}{ }^{10}$ may be associated with vaccine failure, and in the worst case scenario may enhance disease upon viral exposure, either through the induction of enhanced pulmonary macrophage-mediated hyper-inflammation ${ }^{11}$, or $\mathrm{Fc}$ receptor-mediated antibody-dependent enhancement $(\mathrm{ADE})^{12}$. Th1-biasing immunization using CD8 T cells optimized peptide vaccination may offer an important alternative and complementary approach with a history of safe administration, may be developed and updated

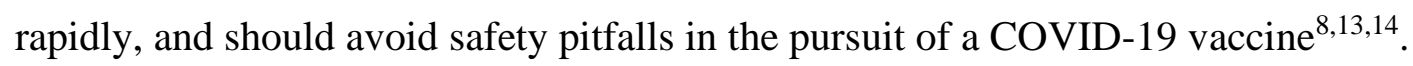


The discovery of memory T lymphocytes resident in diverse tissues, in particular mucosal and barrier tissues, has highlighted the importance of site-specific responses and continuous surveillance mediated by a specific tissue-resident memory $\mathrm{T}$ cell population $(\mathrm{Trm})^{15-17}$. A couple of studies demonstrated that after induction Trm migrate and reside in the lung, skin, and gut long after infection resolution and provide localized protective immunity and immunosurveillance in tissues ${ }^{18-21}$. Trm represents an attractive target population and a growing interest for developing vaccine strategies since they act as immune sentinels in mucosal and barrier tissue and rapidly respond to infection by orchestrating local protective immune responses to eliminate pathogens ${ }^{22}$. Previous CD8 T cell-based vaccines against SARS-CoV-1 $1^{23}$ and influenza $\mathrm{A}^{24}$ viruses showed lasting virus-specific memory CD8 $\mathrm{T}$ cells induction in the spleen, lung and bronchoalveolar fluids (BALs) and protection of mice from lethal SARS-CoV-1 or influenza challenges. Expression of chemokine receptors, such as CXCR3, is critical for CD8+ Trm to populate the airways after vaccination and protection against influenza A viruses ${ }^{25}$. More recently, a Trm-inducing HIV vaccine durably prevented mucosal infection in non-human primates even with lower neutralizing antibody titers ${ }^{26}$. Altogether, these data emphasize the interest of tissue-resident memory viral-specific CD8 T cell generation upon vaccination for optimal protection against airways viruses.

Stimulation of a proper immune response that leads to protection is highly dependent on presentation of epitopes to circulating T-cells via the HLA complex. MEMOPI ${ }^{\circledR}$ is a robust vaccine platform based on selection and immunogenicity optimization of HLA-restricted peptides (neo-epitope) technologies ${ }^{27,28}$ and formulation ${ }^{29}$ for multi-epitopes and targets combination with a pan-DR helper epitope (PADRE) providing help for memory CD8 $\mathrm{T}$ cell generation $^{30}$. A combination of multi-target antitumor neo-epitopes, Tedopi ${ }^{\circledR}$, based on this platform already demonstrated good safety profile and efficacy in clinical Phase 2 trial $^{31}$ and 
more recently successfully validated in the first step of a Phase 3 clinical testing in lung cancer paients $^{32}$. While induction of mucosal immunity using parenteral administration of conventional virus vaccine technologies was challenging, we observed that subcutaneous injection of our neo-epitopes multi-target cancer vaccine promotes Th1-biased antigen-specific memory CD8 T cell responses in the lung and BALs of vaccinated mice in the absence of tumor. Based on this original preclinical observation and the significant survival increase measured during clinical trials in lung cancer patients correlating with epitope responses, we generated and screened individually a large number of immuno-dominant SARS-CoV-2 epitopes, and their neo-epitopes generated using artificial intelligence (AI) algorithms, covering all sequenced circulating SARS-CoV-2 strains and derived from 11 structural (including Spike) and non-structural proteins with significant homology with previous SARS-CoV-1 virus. 


\section{Results}

\section{CD8 T-cell epitopes selection and neo-epitopes design}

Previous research in SARS-CoV-1 suggests that the structural Spike (S) protein is one of the main antigenic component responsible for inducing the host immune responses ${ }^{33}$. However recent evaluation of asymptomatic, moderate and severe convalescent COVID-19 patients showed broad and robust T-cell responses not only on Spike but also on membrane (M), nucleocapsid (N) proteins and several ORFs non-structural proteins $(\mathrm{nsp})^{34-37}$. Deep sequencing data of tens of thousands SARS-CoV-2 genomes from all over the world identified regions that have remained largely invariant to date, and others that have already accumulated significant diversity with several hundreds of point mutations (SNPs) in some key viral proteins, such as the Spike glycoprotein which also displayed a large number of recurrent mutations and several homoplasic sites highlighting a possible convergent evolution and adaptation of SARS-CoV-2 to the human host ${ }^{38-41}$. COVID-19 vaccines reliance on a single antigen (Spike) bearing recurrent mutations and homoplasic sites, as occurring with Spike monovalent vaccines under development, is not without risk of antigen drift, selection pressure and immune evasion ${ }^{42}$.

Using bioinformatics approaches of immune deconvolution to identify $\mathrm{T}$ cell epitopes intersected with predicted SARS-CoV-2 T-cell epitopes reported in early manuscripts ${ }^{43-49}$, population HLA diversity, protein sequence similarity and immunogenicity observed with previous CoVs homologues and the number of copies per virion of SARS-COV-1 ${ }^{50,51}$ (estimated to approximatively 100 copies for S, 1000 for M, 2000 for $\mathrm{N}$ and only 20 for E proteins), we identified and selected 55 HLA-A*0201-restricted T-cell epitopes (9-10 mer peptides) derived from 11 of the 29 SARS-CoV-2 proteins in human cells ${ }^{52}: 3$ out of the 4 structural proteins $(\mathrm{S}, \mathrm{M}, \mathrm{N})$, the largest accessory proteins (ORF3a) and 7 out of the 16 
ORF1a/b non-structural proteins (nsp3, nsp4, nsp6, nsp12, nsp13, nsp14, nsp16) (Figure 1 and Table 1). Based on our knowledge of key fixed-anchor positions to enhance HLA binding and increase their immunogenicity potential, we designed 400 mutated sequences for each individual peptide resulting in 22000 total analyzed sequences of the 55 selected epitopes. We first screened these potential peptides using in-silico bioinformatic analyses (e.g. IEDB Immune epitope database, netMHCpan EL 4.0 algorithm) and a first series of the most optimized mutant for each epitope was selected (neo-epitopes A). In parallel, 22000 in silico HLA-A*0201peptide docking models were generated using computational tools and analyzed using newly developed proprietary artificial intelligence (AI) algorithms based on binding energy calculations and reduction (MabSilico, France). A second series of the most optimized mutant for each epitope was selected (neo-epitopes B). Finally, SARS-CoV-2 genetic evolution analyses through the alignment of 46723 sequences (https://macman123.shinyapps.io/ugiscov2-alignment-screen/) identified recurrent mutation (SNPs) and homoplasic site in SARSCoV-2 genomes isolated globally, particularly in the Spike protein which contain the D614G mutation and which identified the new dominant SARS-CoV-2 variant emerged in February in Europe, then spread worldwide and became the most prevalent form ${ }^{62,63}$. We eliminated $\mathrm{T}$ cell epitopes with recurrent mutation and homoplasic site in order to cover all circulating SARSCoV-2 strains and anticipate future evolution of the virus in hotspot mutation regions.

\section{CD8 T-cell epitopes elicit Tissue-resident memory (Trm) viral-specific T cells in-vivo}

$134 \mathrm{WT}$ and mutated peptides (neoepitopes A and B) were produced using synthetic peptide synthesis (Proteogenix, France). HLA-A2 binding property characterization at $37^{\circ} \mathrm{C}$, using UV peptide exchange assay on HLA-A*0201 monomer, showed that the majority of selected WT epitopes binds to HLA-A2 with good efficacy (Figure 2A) as compared to our MEMOPI ${ }^{\circledR}$ internal positive neoepitope control (mutated peptide with increased HLA-A*0201 binding and 
in-vivo immunogenicity). HLA-A2 binding was increased with several neoepitopes A and/or B, particularly when the corresponding WT peptide showed weak $(<15 \%$ : peptides $2,9,12$, 24, 29 and 35) or intermediate (15-30\%: peptides 4, 14, 16, 18 and 48) HLA-A2 stability at $37^{\circ} \mathrm{C}$. Similarly, several neoepitopes A increased peptide binding to HLA-A2 expressing human cells (TAP-deficient human cell line (T2) lacking the ability to transport peptide fragments to the endoplasmic reticulum to form stable pMHCI) particularly when the corresponding WT peptide showed low (<30\%: peptides 34, 39) or intermediate $(30-60 \%$ : peptides $4,5,21,26,38) \mathrm{HLA}-\mathrm{A} 2$ stability at $37^{\circ} \mathrm{C}$ (Figure 2B). Altogether, bioinformatic and AI-based mutation increased peptides stability with HLA-A2 (recombinant or expressed by cells) for 52\% (26/50) of evaluated CD8 T-cell epitopes.

Finally, 60 peptides (at least one WT or mutated peptides for each T-cell epitopes outside homoplasic site) has been selected based on HLA-A2 binding, peptide stability and SARSCoV-2 genome stability for further in-vivo immunogenicity evaluation in HLA-A2.1 transgenic mice. Mice received a single subcutaneous injection of each peptide combined with the universal PADRE helper T-cell epitope ${ }^{30}$ and emulsified in Montanide ISA-51 adjuvant. Immunogenicity was assessed in the spleen and draining lymph nodes 15 days after vaccination by ex-vivo ELIspot restimulation with the corresponding WT peptide to evaluate crossreactivity of elicited $\mathrm{T}$ cell response towards WT epitopes. IFN $\gamma$ ELIspot after CD8 $\mathrm{T}$ cells restimulation showed large immunogenicity in-vivo responses elicited by single vaccination with 35 out of $60(58 \%)$ positive CD8 T cells epitopes derived from all of the 11 selected proteins (Figure 3A). Similarly, broad immunogenicity response was observed by HLAA*0201-tetramer flow cytometry analyses to a higher number of epitopes since 44 out of 60 (73\%) evaluated peptides, derived from 10 out of the 11 selected proteins, exhibited significant frequency $(0.1-1 \%)$ of viral-specific CD8 T cells (Figure 3B). Phenotypic characterization of 
Tetramer+ cells showed that 17 out of 44 (39\%) positive peptides elicited viral-specific CD8 T cells with mainly a Trm phenotype: co-expressing the memory marker CD44, the CD103 $\alpha \mathrm{E}$ integrin, the Th1-biased CXCR3 chemokine receptor and to a lesser extent the CD49a $\alpha 1$ integrin (Figure 4). Altogether, these data showed that optimized peptide vaccination against selected SARS-CoV-2 epitopes elicits robust and broad Th1-biased immunogenicity against several structural $(\mathrm{S}, \mathrm{M}, \mathrm{N})$ and non-structural proteins in HLA-A2 expressing mice and that several peptides induce viral-specific memory CD8 T cells displaying all characteristics of T lymphocyte sentinels in barrier tissues.

\section{CD8 T-cell epitopes ex-vivo reactivity in asymptomatic and convalescent COVID-19}

\section{individuals compared to unexposed healthy donors}

In order to identify and select naturally SARS-CoV-2 CD8 T cell immunodominant epitopes, peripheral blood mononuclear cells (PBMC) from asymptomatic and moderate or severe COVID-19 patients with a previously confirmed (at least one month before sampling) and recovered SARS-CoV-2 infection were restimulated ex-vivo for one week with each of the 60 selected peptides derived from 11 proteins of SARS-COV-2. IFN $\gamma$ responses over 48 hours of restimulation with HLA-A2+ Tap-deficient (T2) human cells were analyzed and compared to IFN $\gamma$ responses of of unexposed healthy donors. The serology of all unexposed healthy donors was negative while all asymptomatic, moderate and severe COVID-19 individuals were IgG+ for anti-Spike antibodies. As recently reported for CD4+ T cells response ${ }^{64,65}$, we first observed some positive IFN $\gamma$ response in unexposed donors to few CD8 T cells epitopes, in particular for those derived from structural Spike and $\mathrm{N}$ proteins (Figure 5). No response to the Spike_RBD or M structural proteins were observed in unexposed individuals, while CD8 T cell responses to non-structural proteins were limited to nsp12 and nsp13. In contrast, broad positive IFN $\gamma$ response was reproducibly measured against 43 out of 60 selected CD8 T cells epitopes 
derived from all evaluated SARS-CoV-2 proteins $(n=11)$ in convalescent subjects of moderate or severe COVID-19 as well as in asymptomatic individuals but to a lesser extent.

Altogether, when we compared convalescent SARS-CoV-2 individuals to unexposed healthy donors, we identified 25 significantly different CD8 T cell immunodominant epitopes against 3 structural proteins $(\mathrm{S}, \mathrm{M}, \mathrm{N}), 1$ accessory factor (ORF3a) and 7 non-structural proteins (nsp3, nsp4, nsp6, nsp12, nsp13, nsp14, nsp16). 16 of these epitopes are of particular interest for vaccination since they were able to elicit also in-vivo immunogenicity (Elispot response) against all 11 structural and non-structural SARS-CoV-2 proteins after a single peptide injection. Finally, we selected a combination of 12 CD8 T cells epitopes based on manufacturing facilities, HLA-I coverage, previous CoVs homology and SARS-CoV-2 proteins diversity considerations (Table 2). These 12 epitopes covered the 11 selected proteins, 1 epitope/protein excepting Spike for which 2 epitopes (including 1 RBD epitope) have been selected. Bioinformatic analyses illustrate these 12 epitopes are not restricted only to the HLAA*0201 allele, hence are predict (netMHCpan score < 1) to bind efficiently to different HLA-I $(\mathrm{A}, \mathrm{B}, \mathrm{C})$ alleles with high genetic coverage in all geographical region of the world. Despite HLA polymorphism and different worldwide HLA-I distribution, the combination of these 12 T cell epitopes should induce at least 1 to 4 positive peptide responses in all individuals globally and achieve the $60-70 \%$ 'herd immunity' threshold ${ }^{66}$ with at least 4 to 5 positive peptide responses in each geographical region (Table 3). 


\section{Discussion}

Here we report a differentiated SARS-COV-2 vaccine design based on memory T-cell induction technology. Using sequence design through reverse vaccinology selection approach based on previous CoVs knowledge on immunodominant epitopes and computational immunology optimization, we developed a combination of $12 \mathrm{CD} 8 \mathrm{~T}$ cell synthetic peptides originating from 11 SARS-CoV-2 structural and non-structural proteins capable to cover HLA polymorphism with high coverage globally and to induce immunogenicity to different proteins independently of HLA alleles expression. These epitopes are naturally immunogenic after SARS-COV-2 infection in recovered individuals and, for most of them, elicit a specialized sub-population of viral-specific memory CD8 T cells with a tissue-resident phenotype hence capable to migrate, stay attached and patrolling in airways barrier tissues.

Current vaccine approaches using various technology have already showed great anti-Spike antibody induction in Phase 1 and Phase 2 clinical trials as well as some interesting effector T cell responses against the vaccine antigen however without any indication of lasting memory $\mathrm{T}$ cell response ${ }^{67-70}$. Furthermore, this first generation of vaccines are all monovalent, targeting only the Spike or a part of the Spike structural protein and built in urgency using the first Wuhan SARS-CoV-2 sequence. Genomic diversity and hotspot mutations analyses in up to 30000 SARS-CoV-2 genomes, illustrated that the virus had undergone mutations several times already in the last months ${ }^{71}$, adapting itself to its new host, and that new strains bearing significant Spike mutation (e.g. D614G) have emerged, spread globally and became the most prevalent form $^{63}$. Once a mutated virus infects the host cells by escaping the antibodies, it then relies upon the $\mathrm{T}$ cell mediated immunity to fight against the virus. Viral proteins are processed into short peptides inside the infected cells and then loaded onto major histocompatibility complexes (MHC) proteins. After that, the MHC-peptide complexes are presented on the infected cell surface for recognition by specific $\mathrm{T}$ cells. For a universal vaccine, it is hence essential to 
understand genetic evolution and stability of the virus and to select immunodominant $\mathrm{T}$ cell epitopes that originate from conserved regions of the virus covering all circulating strains of SARS-CoV-2 and anticipating future mutation and evolution of the virus which appear more likely in hotspot regions. Similarly, multi-target vaccine are less susceptible to antigenic-drift and virus evasion after immune pression to a single antigen such as with monovalent vaccine.

The discovery of $\mathrm{T}$ cells as residents in tissues has initiated a paradigm shift in the way we study and understand T cell-mediated immunity: from a circulating and surveilling population transiting through barrier tissues to patrolling sentinels at the interface with the outside environment ${ }^{15-17}$. Trm act as immune sentinels and rapidly respond to infection by orchestrating local protective immune responses to eliminate pathogens. Because of their localization directly in tissues, they are able to immediately recognize infected cells or their cognate antigens presented by antigen-presenting cells. Trm protective immunity have been demonstrating to a number of infectious pathogens (viruses, bacteria, fungi, and parasites) in diverse sites such as mucosal and barrier sites (lung, skin, and intestines). In the lung, Trm mediate optimal protection against respiratory viruses such as influenza and respiratory syncytial virus (RSV), whereas circulating memory $\mathrm{T}$ cells and neutralizing antibodies appear to be dispensable $\mathrm{e}^{21,72-}$ 74. Numerous findings indicate now the importance of both CD4+ and CD8+ Trm in tissuelocalized immunity to pathogens, with $\mathrm{CD} 8+$ Trm more prevalent in viral and parasitic infections whereas $\mathrm{CD} 4+$ Trm mediate protection to bacterial and fungal invaders ${ }^{17}$. Furthermore, the CXCR3 chemokine receptor have been reported to be expressed on human lung T-cells and demonstrated to play a significant roles in T-cell homing to the lung parenchyma and ariway since CXCR3 inhibition prevents airway immune responses and vaccine-induced $\mathrm{T}$ cell entry to the lung mucosal compartments ${ }^{75-79}$. Here we showed that, as previously observed with our MEMOPI ${ }^{\circledR}$-based neoepitope cancer vaccine approach, several 
peptides induced viral-specific CD8 T cells expressing the E (CD103) and $\alpha 1$ (CD49a) integrins and the CD44 memory marker, altogether characteristic of Trm. These cells express also the CXCR3 marker of chemoattraction, which is also a surrogate marker of Th1 CD8 T cells since CXCR3 is transactivate directly by the Th1 master gene T-bet ${ }^{79}$. CD103 and CD49a expression are key molecules in Trm biology since providing them the capacity of interaction, adherence and mobility with mucosal tissues, in particular epithelial cells and collagen directly underlying epithelial cells ${ }^{80,81}$.

To summarize, this differentiated Th1-biased memory CD8 T cell SARS-CoV-2 vaccine has been developed using reverse vaccinology selection approach, computational immunology optimization and synthetic peptide synthesis technology. The development of inactivated virus vaccine, besides Good Manufacturing Practices (GMP) system, require extremely high manufacture standard to avoid medical accidents due to the failure of complete inactivation of virus toxicity. Furthermore, different from nucleic acid (e.g. RNA) vaccines, peptide vaccine has relatively more mature manufacturing process. The successful launch of previous peptide vaccines has already demonstrated the safety and efficacy of peptide-based vaccines. The first generation of SARS-CoV-2 vaccine has been based on the first SARS-CoV-2 Wuhan sequence and target only one antigen. Here we propose a second generation of SARS-CoV-2 vaccine taking into consideration virus genetic evolution these last 6 months after global spreading and which targets different structural and key non-structural proteins in stable genome sequence region to cover all circulating SARS-CoV-2 strains and anticipate future virus evolution. Selected T cell epitopes display also very high homology with previous pandemic coronavirus (SARS-CoV-1 and MERS-CoV) and hence may be suitable and ready for future anticipated coronavirus pandemic infection. These preclinical findings on Tissue-resident memory CD8 Tcell responses, providing long-term immunity, were observed after a single injection of a multitarget COVID-19 vaccine. The validation in human PBMC from convalescent asymptomatic, 

made available under aCC-BY-NC 4.0 International license.

moderate and severe COVID-19 patients, support further development of this peptide vaccine anticipating future evolution of the virus in hotspots mutation regions. 


\section{Methods}

\section{Study Approval}

Animal housing and procedures have been conducted according to the guidelines of the French Agriculture Ministry and were approved by the regional ethical committee (APAFIS 25256.) as well as according to the guidelines of Jackson Laboratory (Bar Harbor, USA) and approved by the Institutional Animal Care and Use Committee (IACUC \#20031). Human studies were performed under the clinical protocol COVEPIT-1 approved by French Central Ethic Committee (CPP) and registered by the French Regulatory Authority (ANSM) under the IDRCB $\mathrm{n}^{\circ}$ 2020-A01654-35. Written informed consent has been obtained from each of the participating subject.

\section{HLA-A*0201-peptide binding evaluation}

T-cell WT and mutated peptides binding property on HLA-A2 has been evaluated using the Flex-T HLA-A*02:01 monomer ultraviolet (UV) exchange assay according to the manufacturer recommendation (Biolegend, San Diego, USA). HLA-A*02:01 monomer (200 $\mu \mathrm{g} / \mathrm{ml})$ were exposed to a 366-nm UV lamp in the presence or absence of $400 \mu \mathrm{M}$ of peptide. After UVexposure, HLA-peptide complexes were incubated at $37^{\circ} \mathrm{C}$ for $30 \mathrm{~min}$ to promote unfolding of peptide-free HLA molecule. HLA-peptide complexes stability was detected by ELISA with $\beta 2$ microglobulin coated antibodies and incubation of $3 \mathrm{ng} / \mathrm{ml}$ of complexes for $1 \mathrm{~h}$ at room temperature under shaking condition. Avidin-HRP were used to reveal stable biotinylated HLA-peptide complexes and absorbance was monitored at $450 \mathrm{~nm}$. Data are expressed as percentage of binding relative to an MEMOPI ${ }^{\circledR}$ internal positive control neoepitope. 


\section{SARS-CoV-2 genome diversity evaluation}

A visualization tool was used to determine T-cell and B-cell epitope location in SARS-CoV-2 genomes according to single nucleotide polymorphism (SNPs) and homoplasic site (https://macman123.shinyapps.io/ugi-scov2-alignment-screen/) ${ }^{85} .46723 \quad$ SARS-CoV-2 genomes isolated from patients worldwide were aligned against the Wuhan-Hu-1 reference genome NC_045512.2. A total of 12706 SNPs has been identified corresponding to 398 homoplasic sites with recurrent mutations. Peptides have been blasted with tblastn algorithm against the Wuhan-Hu-1 reference genome NC_045512.2 to determine the nucleotide coordinates for each peptide. The online tool was then used to identify the peptides corresponding to a homoplasic site.

\section{T-cell epitopes immunization}

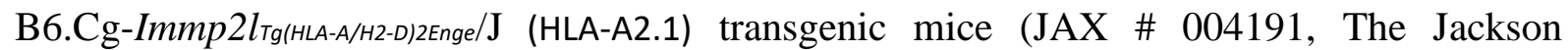
Laboratory, Bar Harbor, USA) received a single subcutaneous injection of 6 SARS-CoV-2 peptides $(50 \mu \mathrm{g}$ each, WT and mutated peptide of a same epitope have not been evaluated in same mice) plus the universal PADRE helper T-cell epitope ${ }^{30}$ emulsified in Montanide ISA-51 adjuvant. Immunization was measured 15 days after injection. 3 males and 3 females have been evaluated per group. Freshly harvested spleen and draining lymph nodes have been pooled by sex per group and analyzed by flow cytometry analyses. CD8+ T cells have been isolated using MACS microbeads and restimulated individualy with each evaluated peptide. The frequency of IFN $\gamma$-secreting CD8+ T cells was measured by ELIspot in parallel of tetramer staining for each peptide evaluated by flow cytometry. 


\section{COVID-19 patient cohorts}

All subjects were enrolled in the COVEPIT-1 clinical trial, an open-label, multicentric and prospective study with minimal risk and constraints designed to assess the memory $\mathrm{T}$ cell in subjects who recovered from COVID-19. Subjects were enrolled at the Groupement Santé du Bataillon des Marins-Pompiers (Marseille-France) and GHR MSA- Hôpital Emile Muller (Mulhouse, France). The main objective was to test the subject' memory T cells reactivity to a selection of SARS-CoV-2 antigens. Enrolled subjects must have a proven COVID-19 infection which recovered 1 to 6 months before study entry. Eligible subjects are male and female of 18 to 70 years old diagnosed for COVID-19 using a PCR test from a nasal and/or oropharyngeal swab, and/or a serological test, and/or a chest CT with lesions suggestive of COVID-19. Subjects were excluded if pregnant or breastfeeding, unable to fulfill the protocol requirement, with an history of cancer 5 years prior to study entry (except for localized or in situ cancer), history of head injury or sepsis 1 year prior to study entry, chronic infections (e.g. HIV infection, chronic hepatitis $\mathrm{B}$, active viral hepatitis $\mathrm{C}$ or bacterial or fungal infection) requiring a systemic treatment in the month prior to COVID-19, disease (auto immune or inflammatory disease, transplant recipients...) requiring a immunosuppressive or immunomodulator treatment and/or, corticosteroids at an equivalent dose of prednisone $>10 \mathrm{mg} / \mathrm{d}$ for more than 15 days or $>40 \mathrm{mg} / \mathrm{d}$ for the last 15 days prior to COVID-19; corticosteroid during COVID-19 were not considered as an exclusion criterion.

\section{Ex-vivo PBMC restimulation with SARS-CoV-2 peptide}

PBMC were isolated after a Ficoll density-gradient centrifugation and a red blood cell lysis. HLA-A2 phenotyping was performed by flow cytometry (clone BB7.2, BD Bioscience). Exvivo stimulation protocol was adapted from a previously described protocol ${ }^{86}$. HLA-A2+ positive PBMC (10\%/well) were incubated in RPMI 1640 containing $10 \mathrm{mM}$ HEPES, $2 \mathrm{mM} \mathrm{L-}$ 
glutamine, 1mM Sodium Pyruvate, $2 \%$ human AB serum, $10 \%$ bovine serum and non-essential amino acids in 48-well plates. During the first week of culture, PBMC were cultured with $3 \mu \mathrm{g} / \mathrm{mL}$ of each isolated peptides and IL-21 (30ng/mL; Miltenyi, Paris France). Fresh medium containing IL-21 (30 ng/mL), IL-7 (5 ng/mL; BioRad, Paris France), and IL-2 (10 ng/mL; Miltenyi, Paris France) and peptide-loaded HLA-A2+ Tap-deficient (T2) cells were added to the culture for the next two days. Ex vivo T-cell viral stimulation was evaluated by IFN $\gamma$ supernatant quantification (BD Biosciences, US). The percentage of background IFN $\gamma$ secretion was determined by the response of PBMC co-cultured with non-loaded T2 cells and negative control peptide, then fold change was calculated over the IFN $\gamma$ secretion background for each donors.

\section{Statistical analysis}

Continuous variables were expressed as the mean \pm SEM, unless otherwise indicated, and raw data were compared with nonparametric tests: Mann-Whitney for 2 groups or Kruskall-Wallis with Dunn's comparison when the number of groups was $>2$. P values of $<0.05$ were considered statistically significant. All statistical analyses were performed on GraphPad Software (GraphPad Software, San Diego, CA).

\section{Acknowledgments}

This work was supported by funding from Nantes Metropole as part of the Metropolitan Fund to Support Health Innovations Linked to the COVID-19 Health Crisis. We thank clinicians and patients involved in the COVEPIT-1 trial as well as the eXYSTAT company for biometric expertise and data management for the COVEPIT-1 trial. 
bioRxiv preprint doi: https://doi.org/10.1101/2020.08.14.240093; this version posted August 14, 2020. The copyright holder for this preprint (which was not certified by peer review) is the author/funder, who has granted bioRxiv a license to display the preprint in perpetuity. It is made available under aCC-BY-NC 4.0 International license. 


\section{References}

1. Wu, L.-P. et al. Duration of Antibody Responses after Severe Acute Respiratory Syndrome. Emerg Infect Dis 13, 1562-1564 (2007).

2. Tang, F. et al. Lack of Peripheral Memory B Cell Responses in Recovered Patients with Severe Acute Respiratory Syndrome: A Six-Year Follow-Up Study. The Journal of Immunology 186, 72647268 (2011).

3. Huang, A. T. et al. A systematic review of antibody mediated immunity to coronaviruses: antibody kinetics, correlates of protection, and association of antibody responses with severity of disease. medRxiv (2020) doi:10.1101/2020.04.14.20065771.

4. Seow, J. et al. Longitudinal evaluation and decline of antibody responses in SARS-CoV-2 infection. medRxiv 2020.07.09.20148429 (2020) doi:10.1101/2020.07.09.20148429.

5. Ibarrondo, F. J. et al. Rapid Decay of Anti-SARS-CoV-2 Antibodies in Persons with Mild Covid-19. New England Journal of Medicine 0, null (2020).

6. Ng, O.-W. et al. Memory T cell responses targeting the SARS coronavirus persist up to 11 years post-infection. Vaccine 34, 2008-2014 (2016).

7. Le Bert, N. et al. SARS-CoV-2-specific T cell immunity in cases of COVID-19 and SARS, and uninfected controls. Nature 1-10 (2020) doi:10.1038/s41586-020-2550-z.

8. Graham, B. S. Rapid COVID-19 vaccine development. Science 368, 945-946 (2020).

9. Iwasaki, A. \& Yang, Y. The potential danger of suboptimal antibody responses in COVID-19. Nature Reviews Immunology 20, 339-341 (2020).

10. Hoepel, W. et al. Anti-SARS-CoV-2 IgG from severely ill COVID-19 patients promotes macrophage hyper-inflammatory responses. http://biorxiv.org/lookup/doi/10.1101/2020.07.13.190140 (2020) doi:10.1101/2020.07.13.190140. 
11. Bolles, M. et al. A double-inactivated severe acute respiratory syndrome coronavirus vaccine provides incomplete protection in mice and induces increased eosinophilic proinflammatory pulmonary response upon challenge. J. Virol. 85, 12201-12215 (2011).

12. Wan, Y. et al. Molecular Mechanism for Antibody-Dependent Enhancement of Coronavirus Entry. J Virol 94, (2020).

13. Peeples, L. News Feature: Avoiding pitfalls in the pursuit of a COVID-19 vaccine. Proceedings of the National Academy of Sciences 117, 8218-8221 (2020).

14. Gilbert, S. C. T-cell-inducing vaccines - what's the future. Immunology 135, 19-26 (2012).

15. Masopust, D., Vezys, V., Marzo, A. L. \& Lefrançois, L. Preferential localization of effector memory cells in nonlymphoid tissue. Science 291, 2413-2417 (2001).

16. Reinhardt, R. L., Khoruts, A., Merica, R., Zell, T. \& Jenkins, M. K. Visualizing the generation of memory CD4 T cells in the whole body. Nature 410, 101-105 (2001).

17. Szabo, P. A., Miron, M. \& Farber, D. L. Location, location, location: Tissue resident memory T cells in mice and humans. Science Immunology 4, (2019).

18. Wakim, L. M., Waithman, J., van Rooijen, N., Heath, W. R. \& Carbone, F. R. Dendritic cellinduced memory T cell activation in nonlymphoid tissues. Science 319, 198-202 (2008).

19. Gebhardt, T. et al. Memory T cells in nonlymphoid tissue that provide enhanced local immunity during infection with herpes simplex virus. Nat. Immunol. 10, 524-530 (2009).

20. Masopust, D. et al. Dynamic T cell migration program provides resident memory within intestinal epithelium. J. Exp. Med. 207, 553-564 (2010).

21. Teijaro, J. R. et al. Cutting edge: Tissue-retentive lung memory CD4 T cells mediate optimal protection to respiratory virus infection. J. Immunol. 187, 5510-5514 (2011).

22. Schenkel, J. M., Fraser, K. A., Vezys, V. \& Masopust, D. Sensing and alarm function of resident memory CD8 ${ }^{+}$T cells. Nat. Immunol. 14, 509-513 (2013). 
23. Channappanavar, R., Fett, C., Zhao, J., Meyerholz, D. K. \& PerIman, S. Virus-Specific Memory CD8 T Cells Provide Substantial Protection from Lethal Severe Acute Respiratory Syndrome Coronavirus Infection. Journal of Virology 88, 11034-11044 (2014).

24. Tan, A. C. L. et al. The design and proof of concept for a CD8+ T cell-based vaccine inducing cross-subtype protection against influenza A virus. Immunology \& Cell Biology 91, 96-104 (2013).

25. B, S., LI, P., Sm, K. \& Jt, H. Lung airway-surveilling CXCR3(hi) memory CD8(+) T cells are critical for protection against influenza A virus. Immunity 39, 939-948 (2013).

26. Arunachalam, P. S. et al. T cell-inducing vaccine durably prevents mucosal SHIV infection even with lower neutralizing antibody titers. Nature Medicine 26, 932-940 (2020).

27. Keogh, E. et al. Identification of new epitopes from four different tumor-associated antigens: recognition of naturally processed epitopes correlates with HLA-A*0201-binding affinity. J. Immunol. 167, 787-796 (2001).

28. Vertuani, S. et al. Improved Immunogenicity of an Immunodominant Epitope of the Her2/neu Protooncogene by Alterations of MHC Contact Residues. The Journal of Immunology 172, 3501-3508 (2004).

29. Beebe, M. et al. Formulation and characterization of a ten-peptide single-vial vaccine, EP2101, designed to induce cytotoxic T-lymphocyte responses for cancer immunotherapy. Hum $\operatorname{Vaccin} 4$, 210-218 (2008).

30. Alexander, J. et al. Development of high potency universal DR-restricted helper epitopes by modification of high affinity DR-blocking peptides. Immunity 1, 751-761 (1994).

31. Barve, M. et al. Induction of immune responses and clinical efficacy in a phase II trial of IDM2101, a 10-epitope cytotoxic T-lymphocyte vaccine, in metastatic non-small-cell lung cancer. J. Clin. Oncol. 26, 4418-4425 (2008).

32. https://ose-immuno.com/wp-content/uploads/2020/04/EN_200401_IDMC-Atalante_VF.pdf.

33. Du, L. et al. The spike protein of SARS-CoV--a target for vaccine and therapeutic development. Nat. Rev. Microbiol. 7, 226-236 (2009). 
34. Grifoni, A. et al. Targets of T Cell Responses to SARS-CoV-2 Coronavirus in Humans with COVID-19 Disease and Unexposed Individuals. Cell 181, 1489-1501.e15 (2020).

35. Sekine, T. et al. Robust T cell immunity in convalescent individuals with asymptomatic or mild COVID-19. bioRxiv 2020.06.29.174888 (2020) doi:10.1101/2020.06.29.174888.

36. Meckiff, B. J. et al. Single-cell transcriptomic analysis of SARS-CoV-2 reactive $C D 4^{+} T$ cells. http://biorxiv.org/lookup/doi/10.1101/2020.06.12.148916 (2020) doi:10.1101/2020.06.12.148916.

37. Bert, N. L. et al. Different pattern of pre-existing SARS-COV-2 specific T cell immunity in SARSrecovered and uninfected individuals. bioRxiv 2020.05.26.115832 (2020) doi:10.1101/2020.05.26.115832.

38. Vankadari, N. Overwhelming mutations or SNPs of SARS-CoV-2: A point of caution. Gene 752, 144792 (2020).

39. van Dorp, L. et al. Emergence of genomic diversity and recurrent mutations in SARS-CoV-2. Infect Genet Evol 83, 104351 (2020).

40. SARS-CoV-2 Alignment Screen. https://macman123.shinyapps.io/ugi-scov2-alignmentscreen/.

41. Laamarti, M. et al. Large scale genomic analysis of 3067 SARS-CoV-2 genomes reveals a clonal geo-distribution and a rich genetic variations of hotspots mutations. bioRxiv 2020.05.03.074567 (2020) doi:10.1101/2020.05.03.074567.

42. Dumonteil, E. \& Herrera, C. Polymorphism and Selection Pressure of SARS-CoV-2 Vaccine and Diagnostic Antigens: Implications for Immune Evasion and Serologic Diagnostic Performance. Pathogens 9, (2020).

43. Ahmed, S. F., Quadeer, A. A. \& McKay, M. R. Preliminary Identification of Potential Vaccine Targets for the COVID-19 Coronavirus (SARS-CoV-2) Based on SARS-CoV Immunological Studies. Viruses 12, (2020). 
44. Campbell, K. M., Steiner, G., Wells, D. K., Ribas, A. \& Kalbasi, A. Prioritization of SARS-CoV-2 epitopes using a pan-HLA and global population inference approach. bioRxiv (2020) doi:10.1101/2020.03.30.016931.

45. Grifoni, A. et al. A Sequence Homology and Bioinformatic Approach Can Predict Candidate Targets for Immune Responses to SARS-CoV-2. Cell Host \& Microbe 27, 671-680.e2 (2020).

46. Prachar, M. et al. COVID-19 Vaccine Candidates: Prediction and Validation of 174 SARS-CoV-2 Epitopes. bioRxiv 2020.03.20.000794 (2020) doi:10.1101/2020.03.20.000794.

47. Bhattacharya, M. et al. Development of epitope-based peptide vaccine against novel coronavirus 2019 (SARS-COV-2): Immunoinformatics approach. Journal of Medical Virology 92, 618-631 (2020).

48. Qiao, R., Tran, N. H., Shan, B., Ghodsi, A. \& Li, M. Personalized workflow to identify optimal Tcell epitopes for peptide-based vaccines against COVID-19. 11.

49. Lee, C. H. \& Koohy, H. In silico identification of vaccine targets for 2019-nCoV. F1000Res 9, (2020).

50. Bar-On, Y. M., Flamholz, A., Phillips, R. \& Milo, R. SARS-CoV-2 (COVID-19) by the numbers. elife 9 ,

51. Neuman, B. W. et al. A structural analysis of M protein in coronavirus assembly and morphology. Journal of Structural Biology 174, 11-22 (2011).

52. Gordon, D. E. et al. A SARS-CoV-2 protein interaction map reveals targets for drug repurposing. Nature 583, 459-468 (2020).

53. Pillay, T. S. Gene of the month: the 2019-nCoV/SARS-CoV-2 novel coronavirus spike protein. Journal of Clinical Pathology 73, 366-369 (2020).

54. Wan, Y., Shang, J., Graham, R., Baric, R. S. \& Li, F. Receptor Recognition by the Novel Coronavirus from Wuhan: an Analysis Based on Decade-Long Structural Studies of SARS Coronavirus. Journal of Virology 94, (2020). 
55. Hoffmann, M. et al. SARS-CoV-2 Cell Entry Depends on ACE2 and TMPRSS2 and Is Blocked by a Clinically Proven Protease Inhibitor. Cell 181, 271-280.e8 (2020).

56. Li, W. et al. Angiotensin-converting enzyme 2 is a functional receptor for the SARS coronavirus. Nature 426, 450-454 (2003).

57. Shang, J. et al. Structural basis of receptor recognition by SARS-CoV-2. Nature $581,221-224$ (2020).

58. Li, F., Li, W., Farzan, M. \& Harrison, S. C. Structure of SARS Coronavirus Spike ReceptorBinding Domain Complexed with Receptor. Science 309, 1864-1868 (2005).

59. Li, F. Structural Analysis of Major Species Barriers between Humans and Palm Civets for Severe Acute Respiratory Syndrome Coronavirus Infections. Journal of Virology 82, 6984-6991 (2008).

60. Yong, C. Y., Ong, H. K., Yeap, S. K., Ho, K. L. \& Tan, W. S. Recent Advances in the Vaccine Development Against Middle East Respiratory Syndrome-Coronavirus. Front. Microbiol. 10, (2019).

61. Smatti, M. K., Al Thani, A. A. \& Yassine, H. M. Viral-Induced Enhanced Disease Illness. Front. Microbiol. 9, (2018).

62. Korber, B. et al. Spike mutation pipeline reveals the emergence of a more transmissible form of SARS-CoV-2. http://biorxiv.org/lookup/doi/10.1101/2020.04.29.069054 (2020) doi:10.1101/2020.04.29.069054.

63. Korber, B. et al. Tracking Changes in SARS-CoV-2 Spike: Evidence that D614G Increases Infectivity of the COVID-19 Virus. Cell (2020) doi:10.1016/j.cell.2020.06.043.

64. Mateus, J. et al. Selective and cross-reactive SARS-CoV-2 T cell epitopes in unexposed humans. Science (2020) doi:10.1126/science.abd3871.

65. Braun, J. et al. SARS-CoV-2-reactive T cells in healthy donors and patients with COVID-19. Nature 1-8 (2020) doi:10.1038/s41586-020-2598-9. 
66. Aguas, R. et al. Herd immunity thresholds for SARS-CoV-2 estimated from unfolding

epidemics. http://medrxiv.org/lookup/doi/10.1101/2020.07.23.20160762 (2020)

doi:10.1101/2020.07.23.20160762.

67. Folegatti, P. M. et al. Safety and immunogenicity of the ChAdOx1 nCoV-19 vaccine against SARS-CoV-2: a preliminary report of a phase $1 / 2$, single-blind, randomised controlled trial. The Lancet 0, (2020).

68. Sahin, U. et al. Concurrent human antibody and TH1 type T-cell responses elicited by a COVID-19 RNA vaccine. medRxiv 2020.07.17.20140533 (2020) doi:10.1101/2020.07.17.20140533.

69. Zhu, F.-C. et al. Immunogenicity and safety of a recombinant adenovirus type-5-vectored COVID-19 vaccine in healthy adults aged 18 years or older: a randomised, double-blind, placebocontrolled, phase 2 trial. The Lancet $\mathbf{0},(2020)$.

70. Jackson, L. A. et al. An mRNA Vaccine against SARS-CoV-2 - Preliminary Report. New England Journal of Medicine 0, null (2020).

71. Alouane, T. et al. Genomic diversity and hotspot mutations in 30,983 SARS-CoV-2 genomes: moving toward a universal vaccine for the "confined virus"? bioRxiv 2020.06.20.163188 (2020) doi:10.1101/2020.06.20.163188.

72. Morabito, K. M. et al. Intranasal administration of RSV antigen-expressing MCMV elicits robust tissue-resident effector and effector memory CD8+ T cells in the lung. Mucosal Immunol 10, 545-554 (2017).

73. Wu, T. et al. Lung-resident memory CD8 T cells (TRM) are indispensable for optimal crossprotection against pulmonary virus infection. J. Leukoc. Biol. 95, 215-224 (2014).

74. Zens, K. D., Chen, J. K. \& Farber, D. L. Vaccine-generated lung tissue-resident memory T cells provide heterosubtypic protection to influenza infection. JCI Insight 1, (2016).

75. Campbell, J. J. et al. Expression of Chemokine Receptors by Lung T Cells from Normal and Asthmatic Subjects. The Journal of Immunology 166, 2842-2848 (2001). 
76. Suzaki, Y. et al. A small-molecule compound targeting CCR5 and CXCR3 prevents airway hyperresponsiveness and inflammation. European Respiratory Journal 31, 783-789 (2008).

77. Jeyanathan, M. et al. CXCR3 Signaling Is Required for Restricted Homing of Parenteral Tuberculosis Vaccine-Induced T Cells to Both the Lung Parenchyma and Airway. The Journal of Immunology 199, 2555-2569 (2017).

78. Ogongo, P., Porterfield, J. Z. \& Leslie, A. Lung Tissue Resident Memory T-Cells in the Immune Response to Mycobacterium tuberculosis. Front. Immunol. 10, (2019).

79. Slütter, B., Pewe, L. L., Kaech, S. M. \& Harty, J. T. Lung Airway-Surveilling CXCR3hi Memory CD8+ T Cells Are Critical for Protection against Influenza A Virus. Immunity 39, 939-948 (2013).

80. Reilly, E. C. et al. TRM integrins CD103 and CD49a differentially support adherence and motility after resolution of influenza virus infection. PNAS 117, 12306-12314 (2020).

81. Cheuk, S. et al. CD49a Expression Defines Tissue-Resident CD8+ T Cells Poised for Cytotoxic Function in Human Skin. Immunity 46, 287-300 (2017).

82. Zost, S. J. et al. Potently neutralizing and protective human antibodies against SARS-CoV-2. Nature 1-7 (2020) doi:10.1038/s41586-020-2548-6.

83. Kim, H. W. et al. Respiratory syncytial virus disease in infants despite prior administration of antigenic inactivated vaccine. Am. J. Epidemiol. 89, 422-434 (1969).

84. Fulginiti, V. A., Eller, J. J., Downie, A. W. \& Kempe, C. H. Altered reactivity to measles virus. Atypical measles in children previously immunized with inactivated measles virus vaccines. JAMA 202, 1075-1080 (1967).

85. Dorp, L. van et al. No evidence for increased transmissibility from recurrent mutations in SARS-CoV-2. bioRxiv 2020.05.21.108506 (2020) doi:10.1101/2020.05.21.108506.

86. Mitra, A. et al. Spatially resolved analyses link genomic and immune diversity and reveal unfavorable neutrophil activation in melanoma. Nature Communications 11, 1839 (2020). 


\section{Figures legends}

Figure 1: $\underline{\text { T-cell epitopes location in SARS-CoV-2 genome }}$

SARS-CoV-2 genome annotation by the Krogran $1 \mathrm{ab}^{52}$ and schematic representation of T-cell epitopes location in each encoded proteins. $n=4$ structural proteins; $n=16$ non-structural proteins (NSPs); $\mathrm{n}=9$ accessory factors.

SARS-CoV-2 genome (bp)

\section{解 T-cell epitopes}


Figure 2: $\underline{\text { HLA-A2 binding characterization of WT and mutated T-cell epitopes }}$

(A) WT and mutated peptides were incubated with HLA-A*02:01 monomer, exposed to UV for peptide exchange and then HLA-peptide complexes stability at $37^{\circ} \mathrm{C}$ was measured by ELISA. Data are mean $+/$ - SEM $(n=4)$ expressed as percentage of binding relative to an internal MEMOPI ${ }^{\circledR}$ positive control neoepitope. (B) WT and mutated peptides $(25 \mu \mathrm{M})$ binding to TAPdeficient human cell line (T2) expressing HLA-A2. Data are expressed as percentage of binding relative to an internal MEMOPI ${ }^{\circledR}$ positive control neoepitope. X mark indicates that the peptide was not tested in the assay.
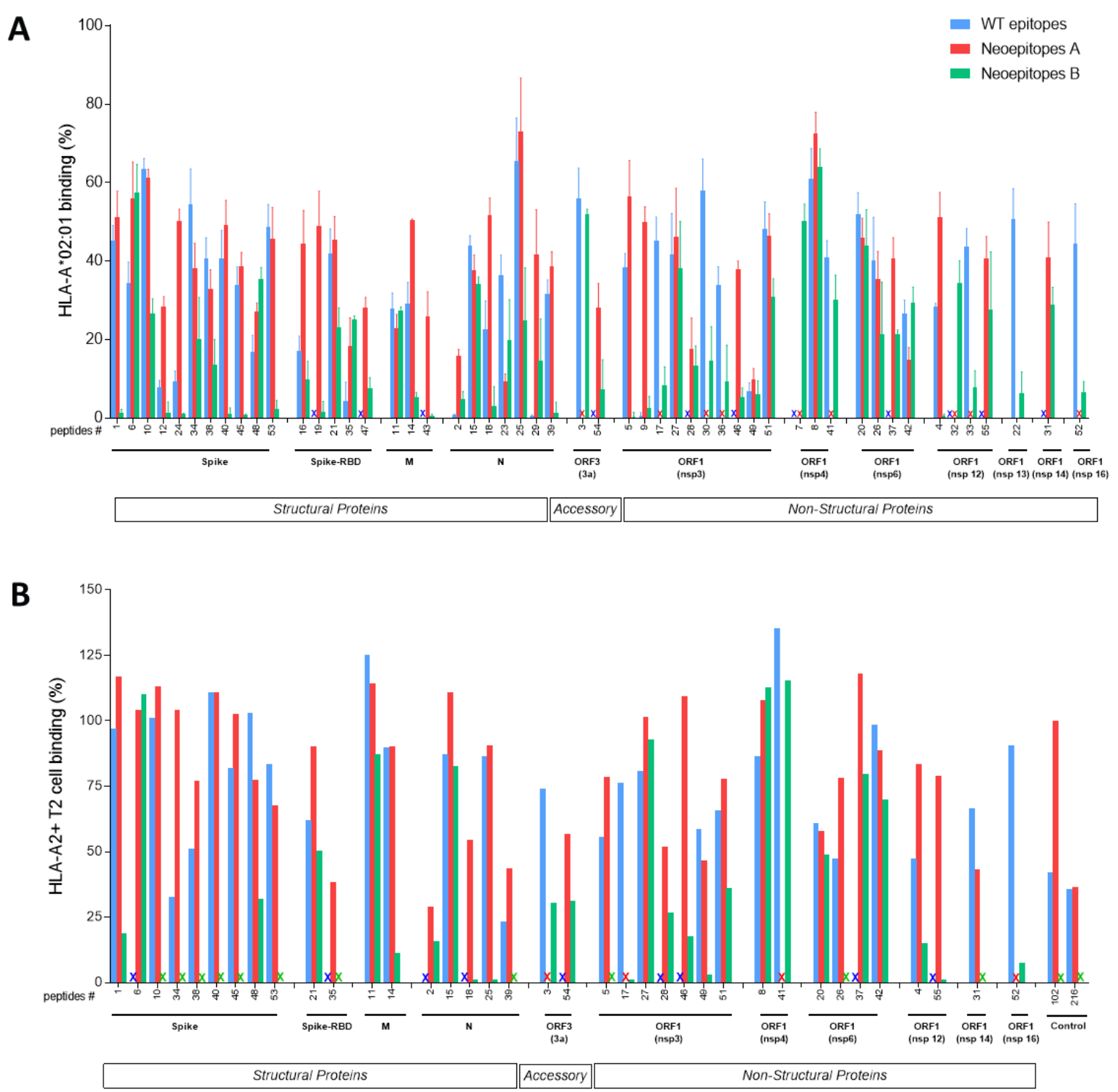


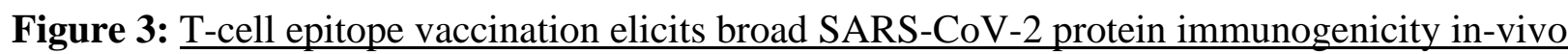

(A) IFN $\gamma$ Elispot responses of pooled spleen and draining lymph nodes cells were restimulated for 24 hours with each of the isolated peptides. Data are mean +/- SEM ( $\mathrm{n}=6)$. Medium level: Three-fold background. High level: Nine-fold background (B) Frequency of Tetramer ${ }^{+}$CD8 T cells $(g a t i n g$ strategy in Figure 4A). Medium and High response threshold were defined based on 2-fold or 3-fold increase respectively compared to the background frequency measured in the non-vaccinated mice control group. Controls+ are MEMOPI ${ }^{\circledR}$ peptides with previously validated immunogenicity. Data are mean $+/-$ SD of pooled female $(n=3)$ and pooled male $(n=3)$ vaccinated mice. Medium level: Two-fold background. High level: Three-fold background

A

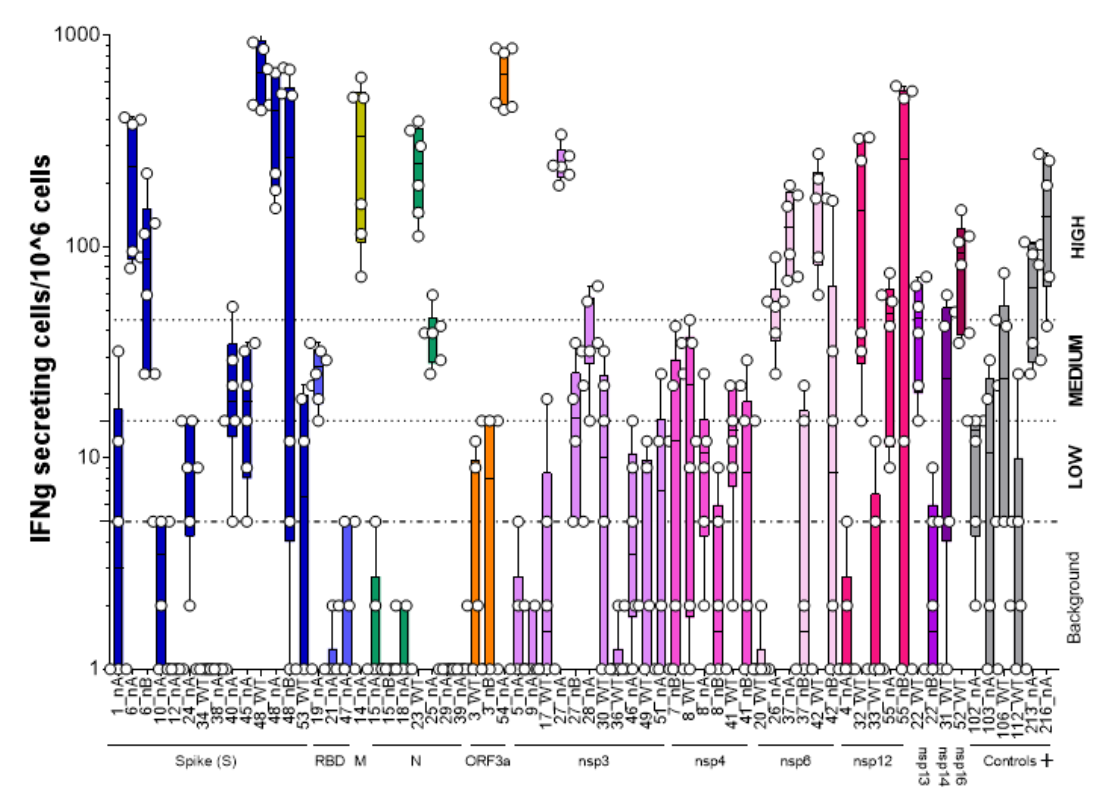

B

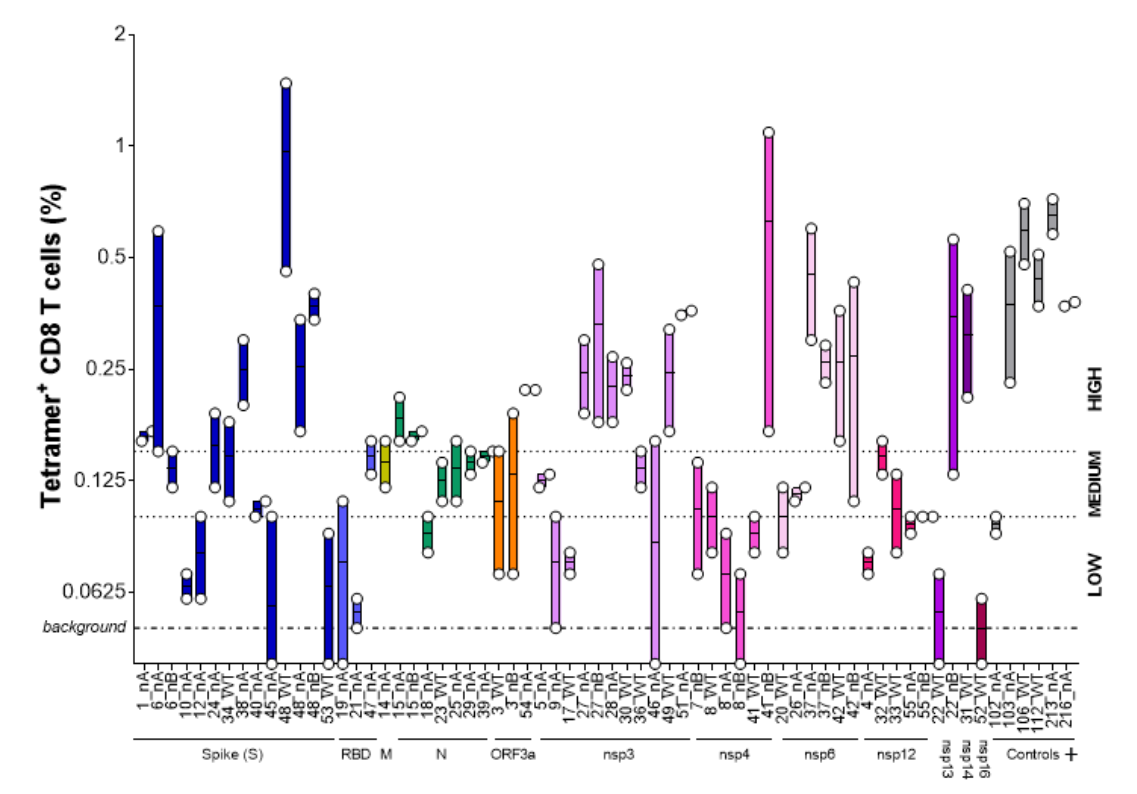


Figure 4: T-cell epitope vaccination elicits Tissue-resident memory viral-specific CD8 T cells

(A) Flow cytometry gating strategy to define Tetramer ${ }^{+}$CD8 T cell responses. (B) Representative example and gating strategy of Trm phenotype based on CD44, CD103, CXCR3, CD49a and CD69 expression in Tetramer ${ }^{+}$CD8 T cells as compared to Tetramer CD8 T cells. (C) Top: Frequency of $\mathrm{CD}_{103}{ }^{+} \mathrm{CD}_{4} 4^{+}$(defined as Trm) cells within Tetramer ${ }^{+} \mathrm{CD} 8 \mathrm{~T}$ cells (defined as medium or high response based on Figure 3). Bottom: Frequency of $\mathrm{CD}_{49} \mathrm{a}^{+}$or $\mathrm{CXCR}^{+}$cells within $\mathrm{Trm}^{+}$Tetramer $^{+} \mathrm{CD} 8 \mathrm{~T}$ cells. Controls + are MEMOPI ${ }^{\circledR}$ peptides with previously validated immunogenicity. Data are mean $+/$ - SD of pooled female $(n=3)$ and pooled male $(n=3)$ vaccinated mice.

A

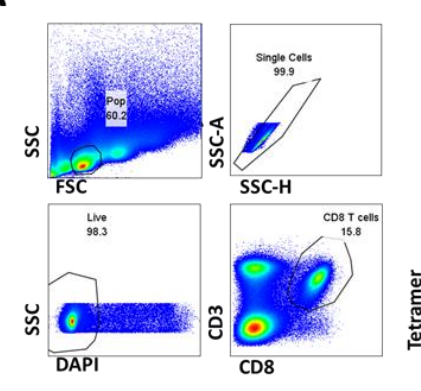

B
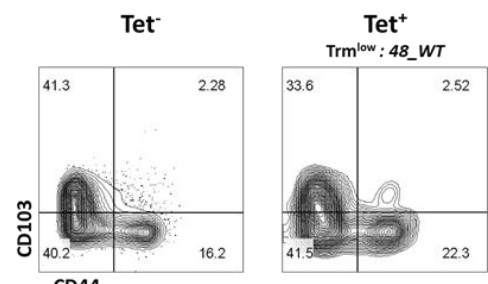

CD8
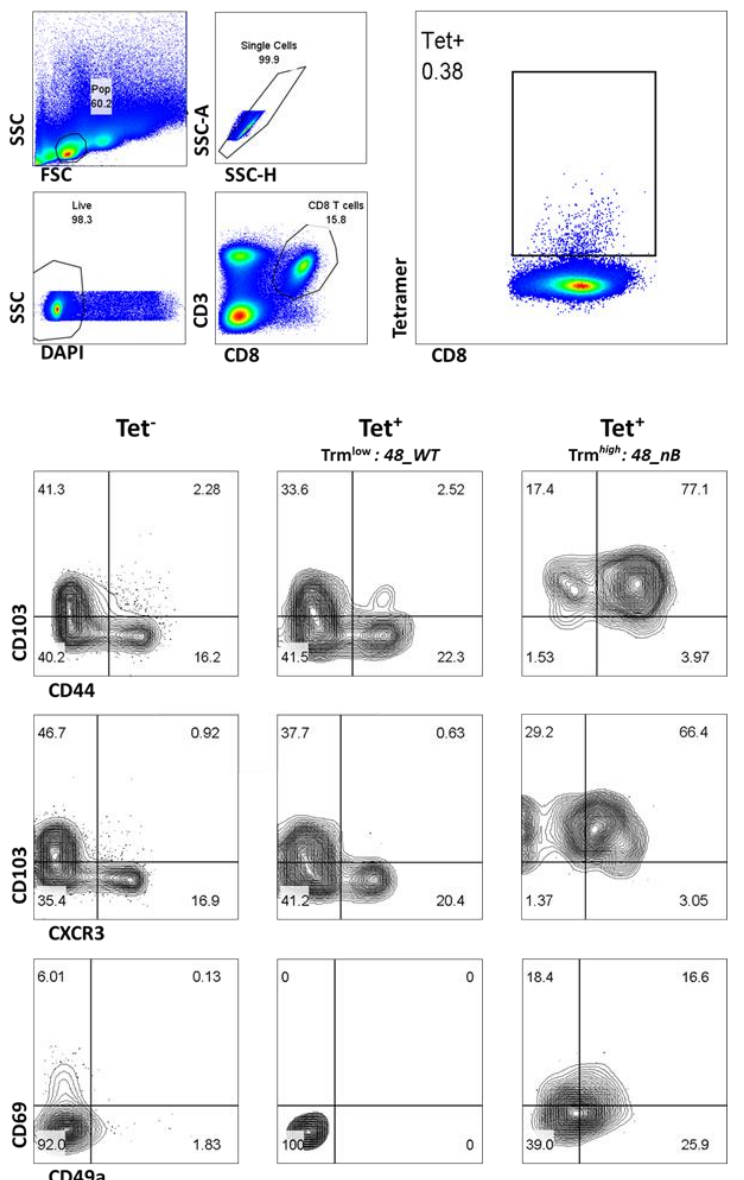

C

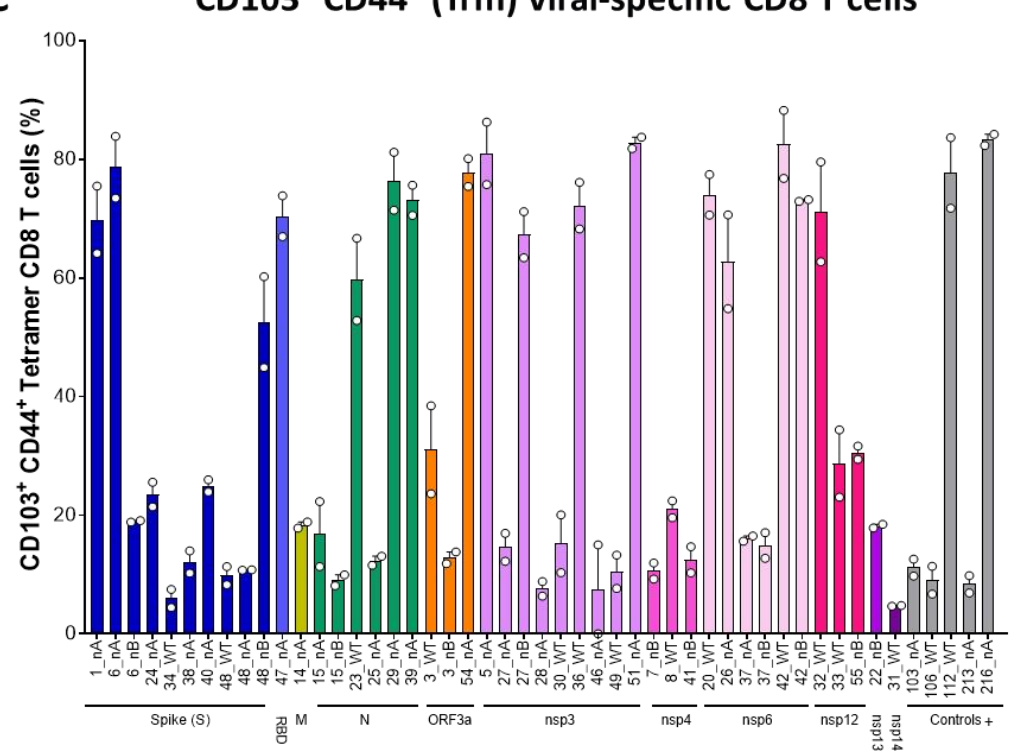

CD49a+ Trm Tet cells

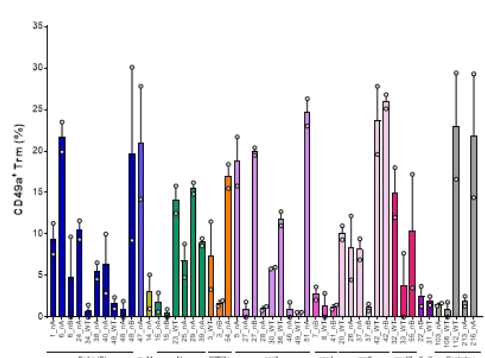

CXCR3 $^{+}$Trm Tet cells

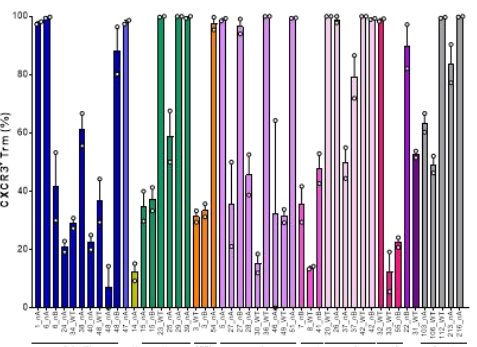


Figure 5: Ex-vivo T-cell epitope reactivity in asymptomatic and convalescent COVID-19 individuals and unexposed donors.

IFN $\gamma$ secretion responses for 48 hours after one week of restimulation of human PBMC from unexposed HLA-A2+ healthy donors ( $\mathrm{n}=5$ ), asymptomatic confirmed COVID-19 HLA-A2+ individuals $(n=4)$ and moderate or severe COVID-19 HLA-A2+ convalescent patients ( $\mathrm{n}=7$ ) with each of the isolated peptides and HLA-A2+ antigen-presenting cells. Data were normalized to negative control peptides. Data are expressed as mean $+/$ - min to max. * ${ }^{*}<0.05$

Spike

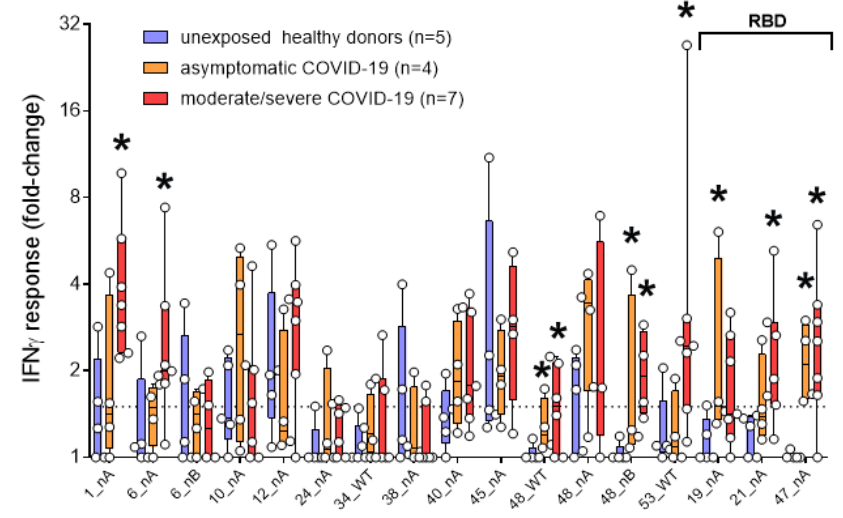

M

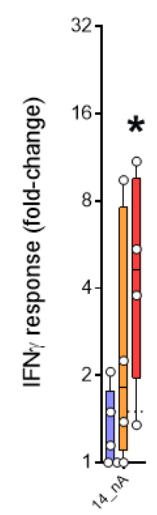

$\mathbf{N}$

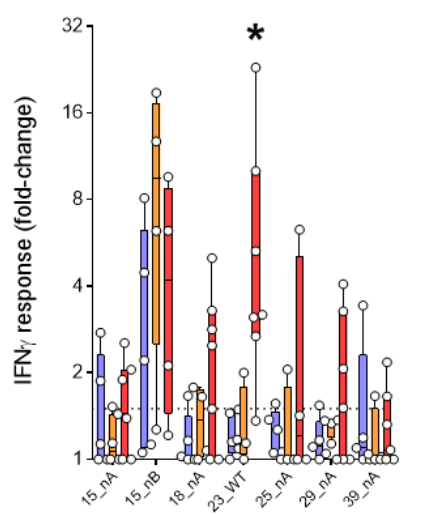

nsp3

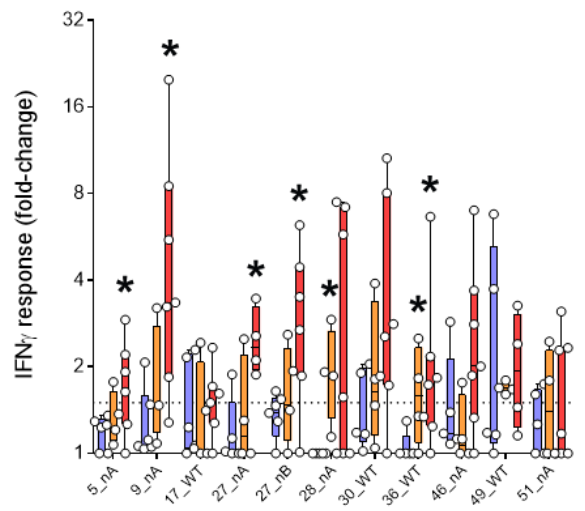

nsp4

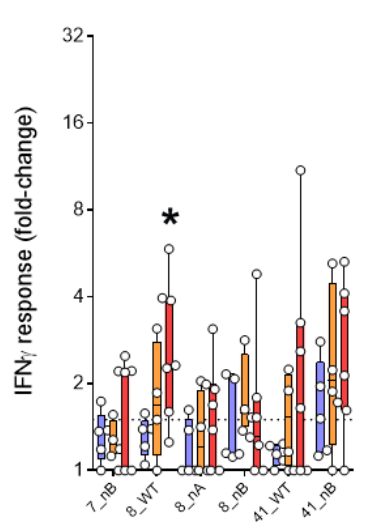

nsp6

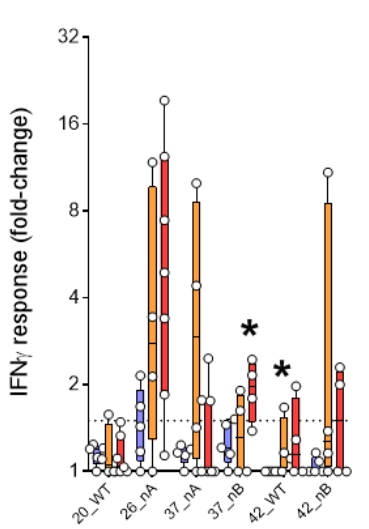

nsp12

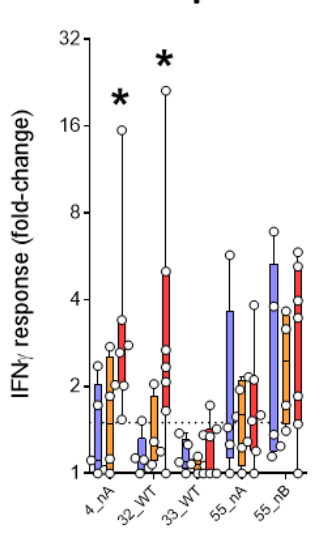

nsp13

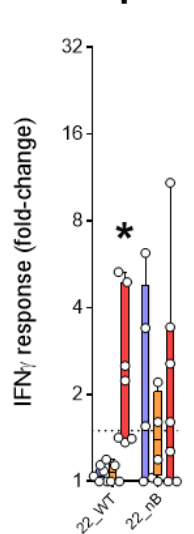

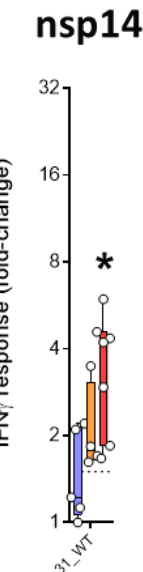

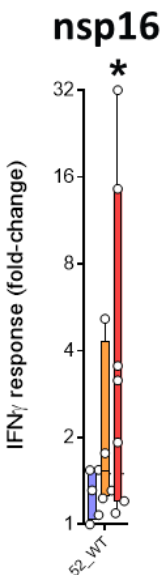

ORF3a

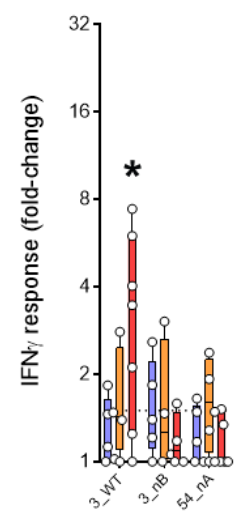


bioRxiv preprint doi: https://doi.org/10.1101/2020.08.14.240093; this version posted August 14, 2020. The copyright holder for this preprint

(which was not certified by peer review) is the author/funder, who has granted bioRxiv a license to display the preprint in perpetuity. It is made available under aCC-BY-NC 4.0 International license.

Table 1: $\underline{\text { T-cell WT epitopes }}$

HLA-I alleles numbers and regional HLA-I coverage were determined using IEDB public database and netMHCpan score $<1$.

\begin{tabular}{|c|c|c|c|c|c|c|c|c|c|c|c|c|c|c|c|c|c|}
\hline peptidelD & target_protein & sequence & start** & end ${ }^{* *}$ & $\underset{\left(H L A \cdot A \cdot A^{02: 01)}\right.}{\text { netMC }}$ & $\begin{array}{l}\text { SARS-CoV } \\
\text { homology }(\%)\end{array}$ & $\begin{array}{c}\text { HLAl alleles } \\
\text { numbers }\end{array}$ & & $\begin{array}{l}\text { LA-I coverage } \\
\text { World }\end{array}$ & & $\begin{array}{l}\text { LA-I coverage } \\
\text { Europe }\end{array}$ & & $\begin{array}{l}\text { A.t coverage } \\
\text { trh America }\end{array}$ & $\begin{array}{l}\text { HLA-1 coverage } \\
\text { South America }\end{array}$ & $\begin{array}{l}\text { HLA-I coverage } \\
\text { Africa }\end{array}$ & & $\begin{array}{l}\text { A-I coverage } \\
\text { Jorth Asia }\end{array}$ \\
\hline 1 & Spike glycoprotein & ALNTLVKQL & 24434 & 24460 & 0.44 & 100 & 9 & 0 & $88,60 \%$ & 0 & $87,88 \%$ & 9 & $91,64 \%$ & $81,51 \%$ & $40,90 \%$ & 0 & $28,24 \%$ \\
\hline 2 & $\mathrm{~N}$ protein & ALNTPKDHI & 28685 & 28711 & 2 & 100 & 2 & 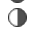 & $39,52 \%$ & 0 & $47,12 \%$ & 0 & $43,14 \%$ & $23,45 \%$ & $23,48 \%$ & 0 & $14,56 \%$ \\
\hline 3 & Protein $3 a$ & ALSKGVHFV & 25606 & 25632 & 0.03 & 71 & 11 & 0 & $90,46 \%$ & 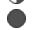 & $90,46 \%$ & e & $92,97 \%$ & $83,89 \%$ & $50,69 \%$ & 0 & $29,43 \%$ \\
\hline 4 & ORF1ab_nsp12 & AMYTPHTVL & 16207 & 16233 & 0.55 & 100 & 45 & c & $99,97 \%$ & 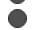 & $100,00 \%$ & 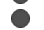 & $99,95 \%$ & $99,19 \%$ & $99,27 \%$ & 0 & $99,67 \%$ \\
\hline 5 & ORF1ab_nsp3 & CLEASFNYL & 6893 & 6919 & 2.4 & 56 & 2 & 0 & $39,52 \%$ & 0 & $47,12 \%$ & 0 & $43,14 \%$ & $23,45 \%$ & (3) $23,48 \%$ & 0 & $14,56 \%$ \\
\hline 6 & Spike glycoprotein & FIAGLIAIV & 25220 & 25246 & 0.1 & 100 & 17 & 0 & $82,72 \%$ & 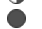 & $87,81 \%$ & 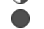 & $82,53 \%$ & $66,28 \%$ & $66,95 \%$ & 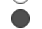 & $81,15 \%$ \\
\hline 7 & ORF1ab_nsp4 & FLAHIOWMV & 9629 & 9655 & 0.03 & 86 & 8 & 0 & $63,88 \%$ & 0 & $66,85 \%$ & 0 & $71,46 \%$ & $50,07 \%$ & $56,23 \%$ & 0 & $44,31 \%$ \\
\hline 8 & ORF1ab_nsp4 & FLLNKEMYL & 9812 & 9838 & 0.01 & 100 & 32 & 0 & $99,94 \%$ & 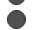 & $99,99 \%$ & 9 & $99,92 \%$ & $98,99 \%$ & $98,81 \%$ & 0 & $99,26 \%$ \\
\hline 9 & ORF1ab_nsp3 & FLTENLLLY & 4007 & 4033 & 1.3 & 67 & 27 & 0 & $95,28 \%$ & 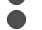 & $98,25 \%$ & 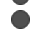 & $95,47 \%$ & $82,13 \%$ & $97,14 \%$ & 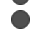 & $88,69 \%$ \\
\hline 10 & Spike glycoprotein & FQFCNDPFL & 21959 & 21985 & 0.36 & 50 & 16 & 0 & $92,11 \%$ & 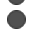 & $89,14 \%$ & 8 & $94,73 \%$ & $88,22 \%$ & $49,41 \%$ & 0 & $73,68 \%$ \\
\hline 11 & M protein & FVLAAVYRI & 26715 & 26741 & 0.2 & 100 & 22 & 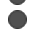 & $87,17 \%$ & 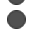 & $90,43 \%$ & 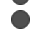 & $87,77 \%$ & $73,27 \%$ & $79,34 \%$ & 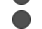 & $87,59 \%$ \\
\hline 12 & Spike glycoprotein & GKQGNFKNL & 22103 & 22129 & 35 & 75 & 2 & 0 & $39,52 \%$ & 0 & $47,12 \%$ & 0 & $43,14 \%$ & $23,45 \%$ & $23,48 \%$ & 0 & $14,56 \%$ \\
\hline 13 & ORF 1ab_nsp14 & GLFKDCSKV & 18055 & 18081 & 0.2 & 89 & 2 & 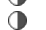 & $40,60 \%$ & 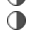 & $47,37 \%$ & 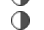 & $44,14 \%$ & $21,85 \%$ & $16,52 \%$ & 0 & $20,34 \%$ \\
\hline 14 & M protein & GLMWLSYFI & 26787 & 26813 & 0.23 & 89 & 2 & () & $40,60 \%$ & () & $47,37 \%$ & () & $44,14 \%$ & $21,85 \%$ & $16,52 \%$ & 0 & $20,34 \%$ \\
\hline 15 & N protein & GMSRIGMEV & 29219 & 29245 & 0.2 & 100 & 3 & 0 & $9,60 \%$ & 0 & $8,90 \%$ & 0 & $10,35 \%$ & $\quad 4,36 \%$ & $14,65 \%$ & 0 & $8,13 \%$ \\
\hline 16 & Spike glycoprotein_RBD & GYQPYRVVVL & 23072 & 23101 & 12 & 100 & 12 & 0 & $89,60 \%$ & 0 & $89,07 \%$ & 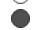 & $83,54 \%$ & $82,73 \%$ & $80,30 \%$ & 0 & $78,67 \%$ \\
\hline 17 & ORF1ab nsp3 & ILLLDQALV & 7970 & 7996 & 0.15 & 100 & 3 & 0 & $42,56 \%$ & 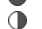 & $48,69 \%$ & 0 & $47,10 \%$ & $23,86 \%$ & $25,12 \%$ & 0 & $20,59 \%$ \\
\hline 18 & $\mathrm{~N}$ protein & ILLNKHIDA & 29324 & 29350 & 0.88 & 100 & 2 & 0 & $39,52 \%$ & 0 & $47,12 \%$ & 0 & $43,14 \%$ & $23,45 \%$ & $23,48 \%$ & 0 & $14,56 \%$ \\
\hline 19 & Spike glycoprotein_RBD & KIADYNYKL & 22811 & 22837 & 0.04 & 100 & 37 & 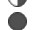 & $99,94 \%$ & 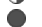 & $99,99 \%$ & 8 & $99,92 \%$ & $99,05 \%$ & $99,17 \%$ & 8 & $99,42 \%$ \\
\hline 20 & ORF1ab_nsp6 & KLKDCVMYA & 11297 & 11323 & 0.37 & 100 & 3 & 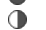 & $43,59 \%$ & 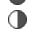 & $49,49 \%$ & ó & $48,75 \%$ & $23,61 \%$ & $25,37 \%$ & 0 & $24,09 \%$ \\
\hline 21 & Spike glycoprotein_RBD & KLPDDFTGCV & 22832 & 22861 & 0.77 & 90 & 2 & e & $40,60 \%$ & 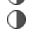 & $47,37 \%$ & o & $44,14 \%$ & $21,85 \%$ & $\quad 16,52 \%$ & 0 & $20,34 \%$ \\
\hline 22 & ORF1ab_nsp13 & KLSYGIATV & 16672 & 16698 & 0.04 & 100 & 14 & 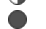 & $92,69 \%$ & 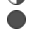 & $91,62 \%$ & 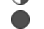 & $94,91 \%$ & $86,66 \%$ & $63,24 \%$ & 0 & $64,80 \%$ \\
\hline 23 & N protein & LALLLLDRL & 28928 & 28954 & 13 & 100 & 9 & 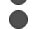 & $88,26 \%$ & 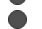 & $84,28 \%$ & 8 & $90,53 \%$ & $83,47 \%$ & $42,02 \%$ & 0 & $62,03 \%$ \\
\hline 24 & Spike glycoprotein & LITGRLQSL & 24548 & 24574 & 3.7 & 100 & 32 & 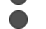 & $99,94 \%$ & 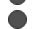 & $99,99 \%$ & - & $99,92 \%$ & $98,99 \%$ & $98,81 \%$ & 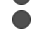 & $99,26 \%$ \\
\hline 25 & $\mathrm{~N}$ protein & LLLDRLNQL & 28937 & 28963 & 0.03 & 100 & 9 & 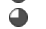 & $65,00 \%$ & 0 & $65,18 \%$ & 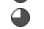 & $68,71 \%$ & $49,58 \%$ & $38,34 \%$ & 0 & $72,87 \%$ \\
\hline 26 & ORF1ab_nsp6 & LLLTLTSL & 11015 & 11038 & 0.2 & 78 & 2 & 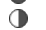 & $40,60 \%$ & () & $47,37 \%$ & 0 & $44,14 \%$ & $21,85 \%$ & $16,52 \%$ & 0 & $20,34 \%$ \\
\hline 27 & ORF1ab_nsp3 & LLSAGIFGA & 3707 & 3733 & 0.21 & 100 & 2 & 0 & $39,52 \%$ & 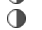 & $47,12 \%$ & o & $43,14 \%$ & $23,45 \%$ & $23,48 \%$ & 0 & $14,56 \%$ \\
\hline 28 & ORF1ab_nsp3 & LMWLIINLV & 7355 & 7381 & 0.94 & 67 & 38 & م & $99,72 \%$ & 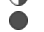 & $99,88 \%$ & 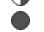 & $99,76 \%$ & $97,73 \%$ & $98,30 \%$ & 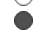 & $99,41 \%$ \\
\hline 29 & N protein & LQLPQGTLL & 28748 & 28774 & 1.8 & 100 & 7 & 0 & $53,32 \%$ & 9 & $63,13 \%$ & 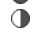 & $56,75 \%$ & $34,91 \%$ & $47,62 \%$ & 0 & $26,11 \%$ \\
\hline 30 & nsp3 & MLAKALRKV & 4199 & 4225 & 0.26 & 67 & 47 & 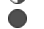 & $99,94 \%$ & 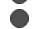 & $99,97 \%$ & 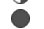 & $99,94 \%$ & $99,46 \%$ & $97,98 \%$ & 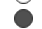 & $99,59 \%$ \\
\hline 31 & ORF1ab_nsp14 & MMISAGFSL & 19537 & 19563 & 0.13 & 100 & 10 & 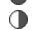 & $58,79 \%$ & 9 & $63,24 \%$ & 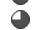 & $63,85 \%$ & $44,67 \%$ & $46,56 \%$ & o & $43,93 \%$ \\
\hline 32 & ORF1ab_nsp12 & NLIDSYFVV & 13630 & 13656 & 0.03 & 89 & 2 & ( & $40,60 \%$ & 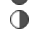 & $47,37 \%$ & 0 & $44,14 \%$ & $21,85 \%$ & $16,52 \%$ & 0 & $20,34 \%$ \\
\hline 33 & ORF1ab_nsp12 & NLLKDCPAV & 13702 & 13728 & 0.19 & 89 & 6 & ( & $52,06 \%$ & 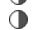 & $56,16 \%$ & 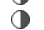 & $57,56 \%$ & $36,34 \%$ & $33,42 \%$ & 0 & $37,43 \%$ \\
\hline 34 & Spike glycoprotein & NLNESLIDL & 25136 & 25162 & 0.19 & 100 & 2 & 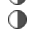 & $39,52 \%$ & 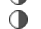 & $47,12 \%$ & 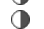 & $43,14 \%$ & $23,45 \%$ & $\quad 23,48 \%$ & 0 & $14,56 \%$ \\
\hline 35 & Spike glycoprotein_RBD & PYRVVVLSF & 23081 & 23107 & 45 & 100 & 2 & ( & $39,52 \%$ & 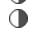 & $47,12 \%$ & 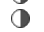 & $43,14 \%$ & - $23,45 \%$ & $23,48 \%$ & 0 & $14,56 \%$ \\
\hline 36 & ORF1ab_nsp3 & QLEMELTPV & 3296 & 3322 & 1.3 & 80 & 4 & 0 & $28,89 \%$ & 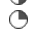 & $23,02 \%$ & 0 & $32,88 \%$ & $30,93 \%$ & $32,53 \%$ & 0 & $30,32 \%$ \\
\hline 37 & ORF1ab_nsp6 6 & RIMTWLDMV & 11249 & 11275 & 0.26 & 75 & 5 & (1) & $48,41 \%$ & 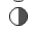 & $54,81 \%$ & () & $51,75 \%$ & - $27,68 \%$ & $33,75 \%$ & C & $26,13 \%$ \\
\hline 38 & Spike glycoprotein & RLNEVAKNL & 25115 & 25141 & 0.25 & 100 & 35 & م & $99,94 \%$ & 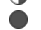 & $99,99 \%$ & 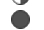 & $99,92 \%$ & $98,96 \%$ & $98,89 \%$ & 0 & $99,48 \%$ \\
\hline 39 & $\mathrm{~N}$ protein & RLNQLESKM & 28949 & 28975 & 1.8 & 89 & 10 & 0 & $37,30 \%$ & (1) & $42,53 \%$ & 0 & $32,20 \%$ & - $19,81 \%$ & $40,16 \%$ & a & $47,60 \%$ \\
\hline 40 & Spike glycoprotein & SIIAYTMSL & 23633 & 23659 & 0.11 & 89 & 44 & 0 & $99,96 \%$ & 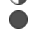 & $100,00 \%$ & 8 & $99,95 \%$ & $99,25 \%$ & $99,15 \%$ & 9 & $99,57 \%$ \\
\hline 41 & ORF1ab_nsp4 & SLPGVFCGV & 9302 & 9328 & 0.2 & 78 & 5 & 0 & $85,99 \%$ & & $82,26 \%$ & 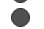 & $90,49 \%$ & $80,91 \%$ & $34,12 \%$ & 0 & $20,74 \%$ \\
\hline 42 & ORF1ab nsp6 & SMWALIISV & 11459 & 11485 & 0.04 & 89 & 8 & 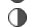 & $53,38 \%$ & 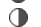 & $58,21 \%$ & 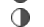 & $58,05 \%$ & $34,82 \%$ & $34,22 \%$ & 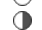 & $44,37 \%$ \\
\hline 43 & M protein & TLACFVLAAV & 26703 & 26732 & 0.84 & 100 & 2 & 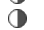 & $39,52 \%$ & 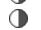 & $47,12 \%$ & 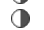 & $43,14 \%$ & $23,45 \%$ & $\quad 23,48 \%$ & 0 & $14,56 \%$ \\
\hline 44 & ORF1ab_nsp6 & TLMNVLTLV & 11393 & 11419 & 0.03 & 89 & 12 & 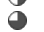 & $65,39 \%$ & 0 & $74,23 \%$ & 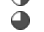 & $67,17 \%$ & $43,82 \%$ & $55,82 \%$ & 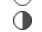 & $46,07 \%$ \\
\hline 45 & Spike glycoprotein & VLNDILSRL & 24488 & 24514 & 0.03 & 100 & 36 & 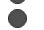 & $99,95 \%$ & & $100,00 \%$ & 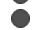 & $99,92 \%$ & $99,04 \%$ & $98,91 \%$ & 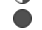 & $99,48 \%$ \\
\hline 46 & ORF1ab_nsp3 & VQMAPISAM & 7379 & 7405 & 1.1 & 89 & 50 & 0 & $99,94 \%$ & & $99,98 \%$ & 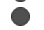 & $99,91 \%$ & $99,10 \%$ & $98,94 \%$ & 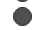 & $99,74 \%$ \\
\hline 47 & Spike glycoprotein_RBD & VSPTKLNDL & 22706 & 22732 & 23 & 89 & 6 & & $90,06 \%$ & & $82,23 \%$ & & $87,33 \%$ & $86,79 \%$ & $12,43 \%$ & (1) & $58,12 \%$ \\
\hline 48 & Spike glycoprotein & VVFLHVTYV & 24740 & 24766 & 0.19 & 100 & 29 & 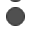 & $99,44 \%$ & e & $99,73 \%$ & 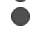 & $99,47 \%$ & $97,26 \%$ & $96,11 \%$ & e & $96,87 \%$ \\
\hline 49 & ORF1ab_nsp3 & WLMWLIINL & 7352 & 7378 & 0.39 & 86 & 2 & 0 & $40,60 \%$ & 0 & $47,37 \%$ & 0 & $44,14 \%$ & $21,85 \%$ & $16,52 \%$ & 0 & $20,34 \%$ \\
\hline 50 & ORF1ab_nsp14 & YLDAYNMMI & 19519 & 19545 & 0.01 & 100 & 36 & 0 & $99,95 \%$ & & $100,00 \%$ & 0 & $99,93 \%$ & $99,15 \%$ & $99,06 \%$ & 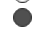 & $99,32 \%$ \\
\hline 51 & ORF1ab_nsp3 & YLNSTNVTI & 7073 & 7099 & 0.04 & 87 & 42 & 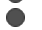 & $99,95 \%$ & 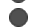 & $100,00 \%$ & 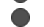 & $99,93 \%$ & $99,17 \%$ & $99,01 \%$ & 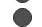 & $99,56 \%$ \\
\hline 52 & ORF1ab_nsp16 & YLNTLTLAV & 20815 & 20841 & 0.03 & 100 & 20 & 0 & $90,44 \%$ & O & $92,42 \%$ & 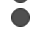 & $91,87 \%$ & $75,46 \%$ & $83,09 \%$ & 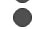 & $91,81 \%$ \\
\hline 53 & Spike 9 & $\mathrm{Yl}$ & 22367 & 22393 & 0. & 67 & 41 & & $99,98 \%$ & 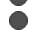 & $100,00 \%$ & & $99,97 \%$ & $99,50 \%$ & $99,47 \%$ & & $99,59 \%$ \\
\hline 54 & Protein 3a & YLYALVYFL & 25711 & 25737 & 0.04 & 89 & 28 & & $99,88 \%$ & 8 & $99,98 \%$ & 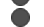 & $99,85 \%$ & $98,75 \%$ & $98,26 \%$ & 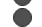 & $97,59 \%$ \\
\hline 55 & ORF1ab_nsp12 & YTMADLVYA & 13804 & 13830 & 0.16 & 100 & 19 & & $81,91 \%$ & & $85,92 \%$ & & $83,57 \%$ & $67,01 \%$ & $74,42 \%$ & 9 & $78,20 \%$ \\
\hline \multicolumn{10}{|c|}{ "*ref_genome_NC_045512.2 } & & $\stackrel{<20 \%}{\circ}$ & & $\frac{20-40 \%}{3}$ & $40-60 \%$ & $>80 \%$ & & $60-80 \%$ \\
\hline
\end{tabular}


bioRxiv preprint doi: https://doi.org/10.1101/2020.08.14.240093; this version posted August 14, 2020. The copyright holder for this preprint

(which was not certified by peer review) is the author/funder, who has granted bioRxiv a license to display the preprint in perpetuity. It is made available under aCC-BY-NC 4.0 International license.

Table 2: $\underline{\text { Selected CD8 T-cell epitopes, previous CoVs homology and HLA-I coverage per }}$ geographic region

\begin{tabular}{|c|c|c|c|c|c|c|c|c|c|c|c|c|}
\hline ID & Epitope & Target & $\begin{array}{c}\text { SARS-CoV } \\
\text { homology } \\
(\%)\end{array}$ & $\begin{array}{c}\text { MERS-CoV } \\
\text { homology } \\
(\%)\end{array}$ & $\begin{array}{c}\text { HLA-I } \\
\text { coverage } \\
\text { WORLD }\end{array}$ & $\begin{array}{c}\text { HLA-I } \\
\text { coverage } \\
\text { EUROPE }\end{array}$ & $\begin{array}{c}\text { HLA-I } \\
\text { coverage } \\
\text { N.E. ASIA } \\
\end{array}$ & $\begin{array}{c}\text { HLA-I } \\
\text { coverage } \\
\text { S. ASIA }\end{array}$ & $\begin{array}{c}\text { HLA-I } \\
\text { coverage } \\
\text { S. AMERICA }\end{array}$ & $\begin{array}{c}\text { HLA-I } \\
\text { coverage } \\
\text { N. AMERICA }\end{array}$ & $\begin{array}{c}\text { HLA-I } \\
\text { coverage } \\
\text { AFRICA }\end{array}$ & $\begin{array}{c}\text { HLA-I } \\
\text { coverage } \\
\text { OCEANIE } \\
\end{array}$ \\
\hline 19_neoA & KIADYNYKL & Spike glycoprotein_RBD & 100 & 77 & $96 \%$ & $98 \%$ & $91 \%$ & $87 \%$ & $96 \%$ & $84 \%$ & $97 \%$ & $90 \%$ \\
\hline 48_neoB & VVFLHVTYV & Spike glycoprotein & 100 & 62 & $96 \%$ & $98 \%$ & $97 \%$ & $90 \%$ & $95 \%$ & $87 \%$ & $95 \%$ & $87 \%$ \\
\hline 23_wt & LALLLLDRL & $\mathrm{N}$ protein & 100 & 70 & $30 \%$ & $27 \%$ & $48 \%$ & $14 \%$ & $33 \%$ & $26 \%$ & $15 \%$ & $27 \%$ \\
\hline 14_neoA & GLMWLSYFI & M protein & 89 & 77 & $41 \%$ & $47 \%$ & $30 \%$ & (19\% & (.) $44 \%$ & $22 \%$ & $17 \%$ & $15 \%$ \\
\hline 54_neoA & YLYALVYFL & Protein 3a & 89 & 62 & $66 \%$ & $70 \%$ & $53 \%$ & (1) $48 \%$ & $72 \%$ & (1) $48 \%$ & $57 \%$ & $45 \%$ \\
\hline 27_neoA & LLSAGIFGA & nsp3 & 100 & 87 & $50 \%$ & $55 \%$ & $31 \%$ & () $25 \%$ & $54 \%$ & $34 \%$ & $36 \%$ & (3) 20\% \\
\hline 8_wt & FLLNKEMYL & nsp4 & 100 & 83 & $99 \%$ & $100 \%$ & $99 \%$ & $95 \%$ & $99 \%$ & $93 \%$ & $99 \%$ & $96 \%$ \\
\hline 42_wt & SMWALIISV & nsp6 & 89 & 66 & $54 \%$ & $58 \%$ & $51 \%$ & () $38 \%$ & $58 \%$ & $35 \%$ & $35 \%$ & (3) $21 \%$ \\
\hline 32_wt & NLIDSYFWV & nsp12 & 89 & 77 & $59 \%$ & $63 \%$ & $51 \%$ & $39 \%$ & $64 \%$ & $45 \%$ & $47 \%$ & $25 \%$ \\
\hline 22_wt & KLSYGIATV & nsp13 & 100 & 77 & $71 \%$ & $76 \%$ & $69 \%$ & (1) $55 \%$ & $74 \%$ & $51 \%$ & (⿹ $63 \%$ & () $62 \%$ \\
\hline 31_wt & MMISAGFSL & nsp14 & 100 & 66 & $99 \%$ & $100 \%$ & $99 \%$ & $95 \%$ & $100 \%$ & $96 \%$ & $98 \%$ & $99 \%$ \\
\hline \multirow[t]{2}{*}{ 52_wt } & YLNTLTLAV & nsp16 & 100 & 88 & $91 \%$ & $92 \%$ & $93 \%$ & $79 \%$ & $92 \%$ & $75 \%$ & $83 \%$ & $88 \%$ \\
\hline & COVEPIT vaccir & 11 SARS-CoV-2 preteins & 96 & 74 & $100 \%$ & $100 \%$ & $100 \%$ & $98 \%$ & $97 \%$ & $100 \%$ & $100 \%$ & $99 \%$ \\
\hline
\end{tabular}


Table 3: Responses to peptides combinations depending on HLA genomic frequency per region

\begin{tabular}{|c|c|c|c|c|c|c|c|c|}
\hline $\begin{array}{c}\text { Combined peptide } \\
\text { response }\end{array}$ & $\begin{array}{l}\text { HLA-I coverage } \\
\text { WORLD }\end{array}$ & $\begin{array}{c}\text { HLA-I coverage } \\
\text { EUROPE }\end{array}$ & $\begin{array}{c}\text { HLA-I coverage } \\
\text { N. AMERICA }\end{array}$ & $\begin{array}{l}\text { HLA-I coverage } \\
\text { S. AMERICA }\end{array}$ & $\begin{array}{l}\text { HLA-I coverage } \\
\text { N.E. ASIA } \\
\end{array}$ & $\begin{array}{l}\text { HLA-I coverage } \\
\text { S. ASIA }\end{array}$ & $\begin{array}{c}\text { HLA-I coverage } \\
\text { AFRICA }\end{array}$ & $\begin{array}{l}\text { HLA-I coverage } \\
\text { OCEANIE }\end{array}$ \\
\hline all 12 peptides & $0 \%$ & $0 \%$ & $0 \%$ & $0 \%$ & $0 \%$ & $0 \%$ & $0 \%$ & $0 \%$ \\
\hline at least 11 peptides & $1 \%$ & $0 \%$ & $1 \%$ & $0 \%$ & $9 \%$ & $5 \%$ & $0 \%$ & $1 \%$ \\
\hline at least 10 peptides & (7) $29 \%$ & () $29 \%$ & $32 \%$ & $20 \%$ & $26 \%$ & $12 \%$ & $14 \%$ & $7 \%$ \\
\hline at least 9 peptides & (9) $35 \%$ & $\bigcirc \quad 36 \%$ & $38 \%$ & $32 \%$ & (9) $32 \%$ & $17 \%$ & $18 \%$ & $14 \%$ \\
\hline at least 8 peptides & (9) $32 \%$ & ( $33 \%$ & ( $35 \%$ & ( $24 \%$ & () $27 \%$ & $15 \%$ & $16 \%$ & $9 \%$ \\
\hline at least 7 peptides & $42 \%$ & (1) $43 \%$ & $44 \%$ & (1) $40 \%$ & () $34 \%$ & $25 \%$ & ( $26 \%$ & $17 \%$ \\
\hline at least 6 peptides & $54 \%$ & $56 \%$ & $55 \%$ & $47 \%$ & (1) $49 \%$ & $39 \%$ & $47 \%$ & $33 \%$ \\
\hline at least 5 peptides & $75 \%$ & $75 \%$ & $76 \%$ & $69 \%$ & $69 \%$ & $58 \%$ & ( $64 \%$ & $54 \%$ \\
\hline at least 4 peptides & $100 \%$ & $100 \%$ & $99 \%$ & $100 \%$ & $99 \%$ & $91 \%$ & $85 \%$ & $65 \%$ \\
\hline at least 3 peptides & $100 \%$ & $100 \%$ & $100 \%$ & $100 \%$ & $100 \%$ & $100 \%$ & $100 \%$ & $67 \%$ \\
\hline at least 2 peptides & $100 \%$ & $100 \%$ & $100 \%$ & $100 \%$ & $100 \%$ & $100 \%$ & $100 \%$ & $82 \%$ \\
\hline at least 1 peptide & $100 \%$ & $100 \%$ & $100 \%$ & $100 \%$ & $100 \%$ & $100 \%$ & $100 \%$ & $100 \%$ \\
\hline
\end{tabular}

